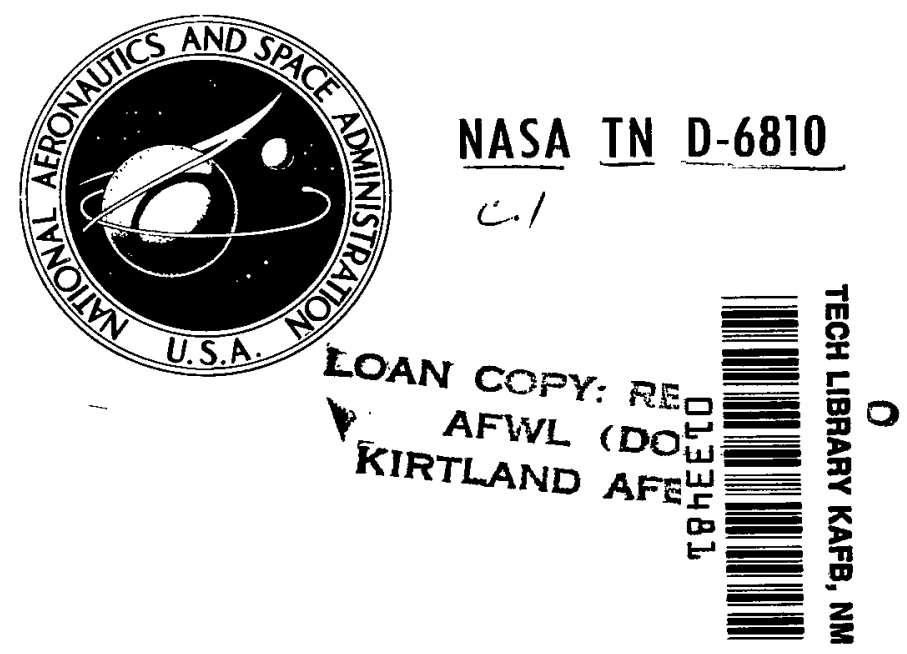

\title{
ALLOY HARDENING AND SOFTENING IN BINARY MOLYBDENUM ALLOYS AS RELATED TO ELECTRON CONCENTRATION
}

by Joseph R. Stephens and Walter R. Witzke Lewis Research Center

Cleveland, Obio 44135

NATIONAL AERONAUTICS AND SPACE ADMINISTRATION - WASHINGTON, D. C. - MAY 1972 
1. Report No. NASA TN D-6810

4. Title and Subtitle ALLOY HARDENING AND SOFTENING IN BINARY MOLYBDENUM ALLOYS AS RELATED TO ELECTRON CONCENTRATION

7. Author(s)

Joseph R. Stephens and Walter R. Witzke

9. Performing Organization Name and Address

Lewis Research Center

National Aeronautics and Space Administration

Cleveland, Ohio 44135

12. Sponsoring Agency Name and Address

National Aeronautics and Space Administration

Washington, D. C. 20546

15. Supplementary Notes

16. Abstract

An investigation was conducted to determine the effects of alloy additions of hafnium, tantalum, tungsten, rhenium, osmium, iridium, and platinum on the hardness of molybdenum. Special emphasis was placed on alloy softening in these binary molybdenum alloys. Results showed that alloy softening was produced by those elements having an excess of s+d electrons compared to molybdenum, while those elements having an equal number or fewer s+d electrons than molybdenum failed to produce alloy softening. Alloy softening and alloy hardening can be correlated with the difference in number of $s+d$ electrons of the solute element and molybdenum.
17. Key Words (Suggested by Author(s)) Hardness Molybdenum alloys Alloy hardening Electron-to-atom ratio
18. Distribution Statement

Unclassified - unlimited

Alloy softening 


\title{
ALLOY HARDENING AND SOFTENING IN BINARY MOLYBDENUM
}

\author{
ALLOYS AS RELATED TO ELECTRON CONCENTRATION \\ by Joseph R. Stephens and Walter R. Witzke \\ Lewis Research Center
}

\section{SUMMARY}

An investigation was conducted to determine the effects of alloy additions of hafnium, tantalum, tungsten, rhenium, osmium, iridium, and platinum on the hardness of molybdenum. Special emphasis was placed on alloy softening in these binary molybdenum (Mo) alloys. A modified microhardness test unit permitted hardness determinations at homologous temperatures ranging from 0.02 to 0.15 , where alloy softening normally occurs in body-centered cubic alloys. Alloys were prepared by arc-melting high-purity electron-beam-melted Mo and high-purity alloying elements. Alloy additions ranged from less than 1 atomic percent up to the maximum solubility of each of the elements in Mo. Hardness was determined for at least six alloys from each alloy system at four test temperatures in order to fully characterize alloy softening in these binary Mo alloys.

Results showed that alloy softening was produced by those elements having an excess of $\mathrm{s}+\mathrm{d}$ electrons compared to Mo, while those elements having an equal number or fewer $s+d$ electrons than Mo failed to produce alloy softening.

The magnitude of the softening and the amount of solute element at the hardness minimum diminished rapidly with increasing test temperature. At solute concentrations where alloy softening was observed, the temperature sensitivity of hardness was lowered. For solute elements having an excess of $s+d$ electrons or fewer $s+d$ electrons than Mo alloy softening and alloy hardening can be correlated with the difference in number of $s+d$ electrons of the solute element and Mo. These results point to an intrinsic property controlling low-temperature deformation of Mo alloyed with the transition elements of the sixth period.

\section{INTRODUCTION}

In a previous study (ref. 1), the authors showed that alloy softening in the group VIA 
metals chromium ( $\mathrm{Cr}$ ), molybdenum (Mo), and tungsten (W) alloyed with rhenium (Re) was similar in all three alloy systems, occurring at homologous temperatures less than 0.16 and at Re concentrations less than 16 atomic percent. The results of that study led to the conclusions that alloy softening in group VIA - Re alloys is controlled by an intrinsic property and that electron concentration plays a dominant role in the hardness behavior of these alloy systems.

Alloy softening in other body-centered cubic alloys continues to attract much interest on the part of numerous investigators (ref. 2). One common factor noted in these studies is that alloy systems that exhibit alloy softening also exhibit a temperature dependence of yield stress, flow stress, or hardness that is less than that of the solvent metal. However, investigators are not in agreement on the mechanism producing alloy softening. Especially in the group VA metals vanadium (V), niobium (Nb), and tantalum (Ta) there is disagreement on whether alloy softening results from an extrinsic factor such as scavenging of interstitial impurities or from an intrinsic factor such as lowering of the Peierls stress. For example, Hasson and Arsenault (ref. 3), using internal friction techniques, showed that in a Ta - 2-atomic-percent-W alloy doped with oxygen tungsten does not act as a scavenger. The Ta-W alloy system had previously been shown to exhibit alloy softening (ref. 4). Similar results were obtained for a Ta - 9.2atomic-percent- $\mathrm{Nb}$ alloy doped with oxygen. In contrast, internal friction results for a $\mathrm{V}$ - 1.3-atomic-percent- Ti alloy doped with oxygen indicated that $\mathrm{Ti}$ was acting as a scavenger. This was expected because of the high affinity of titanium for oxygen. Hasson and Arsenault attributed alloy softening in all three alloy systems to an intrinsic effect, lowering of the Peierls stress.

Sagues and Gibala (ref. 5), using internal friction techniques, have shown that in Ta-Re-nitrogen (N) alloys Re scavenges $N$ and that alloy softening in this system may be due to an extrinsic factor, the $\mathrm{Re}-\mathrm{N}$ interaction.

The results on group VA metals suggest that two possible mechanisms may cause alloy softening in these metals. For the group VIA metals the only systematic study of alloy softening is the recent investigation by the authors (ref. 1), where an intrinsic factor was postulated to be responsible for alloy softening.

The purpose of the present investigation was to further characterize alloy softening in one of the group VIA metals, Mo, and to determine the role of electron concentration on the hardness behavior of Mo. Alloy additions included the transition metals from the sixth period, hafnium (Hf), Ta, W, Re, osmium (Os), iridium (Ir), and platinum (Pt). Solute contents ranged from less than 1 atomic percent up to the maximum solubility of solute in Mo. At least six alloys from each system were tested over a homologous temperature range of 0.02 to 0.15 in a modified microhardness test unit. 


\section{SYMBOLS}

a lattice parameter

$\mathrm{C}_{\mathrm{S}} \quad$ solute atomic fraction

$\mathrm{C}_{\mathrm{Mo}}$ molybdenum atomic fraction

e/a electron-atom ratio

$\Delta \mathrm{F}_{\mathrm{f}}^{\mathrm{O}}$ standard free energy of formation

$\mathrm{H}$ hardness

$\mathrm{T}_{\mathrm{m}} \quad$ absolute melting temperature of unalloyed molybdenum

VHN Vickers hardness number

$\Delta \mathrm{V}$ difference in number of $\mathbf{s}+\mathrm{d}$ electrons

$\Omega \quad C_{\mathrm{S}}^{1 / 2} \Delta \mathrm{V}$

\section{EXPERIMENTAL PROGRAM}

\section{Materials}

Table I presents the nominal and analyzed compositions of unalloyed Mo and the fifty binary Mo alloys employed in this investigation. Interstitial analyses are also listed in table I for two alloys from each alloy system. Materials used for this study included high-purity electron-beam-melted Mo, Ta, W, and Re; commercial-purity Hf turnings and Pt foil; and hydrogen-annealed Os and Ir powders. Ingots were prepared by nonconsumable triple-arc-melting of 70-gram charges in a water-cooled copper mold followed by drop casting into a square-cross-section mold.

Slices approximately 3 millimeters thick by 15 millimeters long were cut from the cast ingots for hardness testing. Specimens were annealed in vacuum for 1 hour at $0.7 \mathrm{~T}_{\mathrm{m}}$ or at a higher temperature within the solid solution range in order to reduce segration and produce single-phase, equiaxed, strain-free specimens. Specimens were given a metallographic polish on the face to be hardness tested.

\section{Apparatus}

The modified microhardness test unit used in this study has previously been described (ref. 1). The test unit permitted hardness testing over the temperature range 77 to $411 \mathrm{~K}$. 


\section{Procedure}

Alloying elements selected for this study are shown in the partial periodic table in figure 1. Alloying elements are all from the sixth period and include the transition elements Hf through Pt. Solute contents were selected to give equivalent electron-atom ratios in alloys whose solute elements have fewer $s+d$ electrons than Mo (Hf and $\mathrm{Ta}$ ). Solute contents were similarly selected for those elements having an excess of $s+d$ electrons compared to Mo (Re, Os, Ir, and Pt). Additions of W were excluded from this basis for alloy composition selection since Mo and $W$ have the same number of $s+d$ electrons. Solute contents were also chosen to cover the solubility range of each solute in Mo, which can be seen in figure 2 (refs. 6 to 9) to vary from a minimum of only a few atomic percent for Pt in Mo up to complete solubility for the Mo-Ta and Mo-W alloy systems.

Test temperatures were selected to cover approximately the temperature range where alloy softening is observed, less than $0.16 \mathrm{~T}_{\mathrm{m}}$ for Mo-Re alloys (ref. 1). Test temperatures in equivalent increments included 77, 188, 300, and $411 \mathrm{~K}$ or $0.027,0.065$, 0.104 , and $0.143 \mathrm{~T}_{\mathrm{m}}$, respectively.

A minimum of 10 diamond pyramid hardness impressions were made on each alloy at each test temperature. A load of 1 kilogram and a dwell time of 15 seconds were used for the impressions. Hardness readings were taken only of impressions within the grains. The relative standard deviation was 5 percent.

\section{RESULTS}

\section{Solute Effects}

As noted in figure 2, two of the sixth period elements, Ta and $\mathrm{W}$, are totally soluble in Mo. The hardnesses of these two alloy systems at $300 \mathrm{~K}$ are included in figure 3 . It should be noted that $\mathrm{Ta}$ additions produce apparent parabolic hardening of Mo and that maximum hardness in this system occurs near 50 atomic percent Ta. In contrast, W additions produce nearly linear hardening of Mo with hardnesses lying close to a straight line connecting the hardness values for unalloyed Mo and $\mathrm{W}$.

A dramatic difference in hardness behavior is observed for alloying elements having intermediate or limited solubility in Mo. Results for Re and Pt additions from this study as well as results reported in the literature (refs. 10 to 16) are also shown in figure 3. It should be noted that for Re additions at $300 \mathrm{~K}$ an initial softening of Mo occurs followed by apparent parabolic hardening up to the solubility limit of Re in Mo, near 40 atomic percent. Formation of the $\sigma$ phase produces an extremely high hard- 
ness in the Mo-Re system, and finally near the Re rich end of the Mo-Re system hardness decreases to the value for unalloyed Re.

Hardness for the Mo-Pt system, based on the available data from this study and data reported in the literature, apparently reaches a maximum near the maximum solubility of Pt in Mo. Within the solid solution range of $\mathrm{Pt}$ in Mo hardness increases rapidly with increase in Pt content.

Table II summarizes the hardness data for the seven alloy systems investigated. These data are presented graphically in figure 4. It should be noted in figures 4(a) to (c) that Hf, Ta, and $\mathrm{W}$ additions produce hardening of Mo over the entire homologous temperature range of 0.027 to $0.143 \mathrm{~T}_{\mathrm{m}}$, where alloy softening was observed in Mo-Re alloys (ref. 1). In contrast, alloy additions of Re, Os, Ir, and Pt produce an initial softening of Mo at low solute contents and at low temperatures (figs. 4(d) to (g)). At higher solute concentrations and higher temperatures hardening of Mo is observed. The amount of solute required to produce a hardness minimum in each of these four systems is noted (1) to increase with decreasing temperature in agreement with previous observations on group VIA - Re alloys (ref. 1) and (2) to decrease with increasing s+d electrons.

\section{Temperature Effects}

The temperature dependence of hardness is illustrated in figure 5 for unalloyed Mo and the seven alloy systems investigated. Hardness in figure 5 is noted to decrease monotonically with temperature for unalloyed Mo and the binary Mo alloys. Examination of figures $5(\mathrm{~d})$ to $(\mathrm{g})$ shows that dilute additions of Re, Os, Ir, and Pt resulted in a marked decrease in the temperature dependence of hardness compared to unalloyed Mo. This decrease in temperature dependence of hardness or yield stress with alloying is characteristic of alloy softening in body-centered cubic metals, having been observed in group VIA - Re alloys by the authors (ref. 1) and in other body-centered cubic metals exhibiting alloy softening (refs. 2, 4, and 5). Additions of Hf and Ta also lower the temperature sensitivity of hardness, but not sufficiently to produce softening.

\section{DISCUSSION OF RESULTS}

The purpose of this section of the report is to analyze the hardness data in terms of current theories of alloy softening and hardening and to illustrate that electron concentration plays a dominant role in the hardness behavior of binary Mo alloys. 


\section{Scavenging}

The available standard free energy of formation $\Delta F_{f}^{o}$ (ref. 17) data for compounds of the sixth period elements with carbon (C), oxygen $(\mathrm{O})$, and $\mathrm{N}$ (at $2000 \mathrm{~K}$ ) are listed in table III. Based on the data in table III it is postulated that Hf and Ta would be expected to be potential scavengers of all the interstitials listed. From a comparison of the values of $\Delta \mathrm{F}_{\mathrm{f}}^{\mathrm{O}}$ for the oxides of the sixth period elements, those elements producing alloy hardening, $\mathrm{Hf}, \mathrm{Ta}$, and $\mathrm{W}$, would be expected to scavenge oxygen from the Mo lattice. Of the elements producing alloy softening, Re, Os, Ir, and Pt (figs. 4(d) to (g)), only Os would be expected to scavenge oxygen from Mo. If all the oxygen in Mo is in solution, thermodynamic calculations show that $\mathrm{Hf}$ at the same concentration as Os at the hardness minimum at $77 \mathrm{~K}$, i.e., 1.72 atomic percent, to be a much more effective scavenger of oxygen than is Os. However, softening is not observed in Mo-Hf alloys. From these calculations the equilibrium amount of oxygen left in solution in a Mo-Hf alloy would be several orders of magnitude less than in a Mo-Os alloy.

Data are not available to make a similar comparison for carbides and nitrides, possibly because Re, Os, Ir, and Pt do not form stable carbides and nitrides.

The thermodynamic calculations coupled with derivations of alloy softening for Mo-Re, Mo-Os, Mo-Ir, and Mo-Pt alloys and only alloy hardening in Mo-Hf, Mo-Ta, and Mo-W alloys indicate that interstitial scavenging, i.e., chemical combination of solute and interstitial, is not responsible for alloy softening in the binary Mo alloys under investigation.

This conclusion does not exclude the idea of solute-interstitial association proposed by Sagues and Gibala (ref. 5). It is not known if this mechanism can explain the absence of alloy softening in Mo-Hf, Mo-Ta, and Mo-W alloys.

\section{Atomic Size Misfit}

It has been shown by Fleischer (ref. 18) that solution hardening can be correlated with atomic size misfit or modulus misfit factors between solute and solvent for a number of alloys of copper or silver. More recently Mitchell and Raffo (ref. 19) have shown that the rate of alloy hardening for body-centered cubic alloys is proportional to the atomic misfit parameter as measured by the rate of change in the lattice parameter.

Teatum, Gschneidner, and Waber (ref. 20) have recently calculated the atomic radii for a number of solutes in Mo. The calculated atomic radius ratios of solute elements to Mo are shown in figure 6 and the change in lattice parameter of Mo upon alloying with the sixth period elements based on the data of Pearson (refs. 21 and 22) is shown in figure 7. Lattice parameter data for Mo- Pt alloys were not given by Pearson, 
but our measurements and those of Ocken and Van Vucht (ref. 9) show that the lattice parameter of Mo is unchanged with additions of up to 12 atomic percent Pt. Comparison of the change in lattice parameter of Mo with the calculated atomic radius ratio reveals that the change in lattice parameter is what would be expected from atomic size effects. Those elements that are larger than Mo increase the lattice parameter and those that are smaller than Mo decrease the lattice parameter. The rate of increase or decrease in lattice parameter is directly proportional to the atomic radius ratio.

In figure 8(a) the initial rate of hardening for the binary Mo alloys $\mathrm{dH} / \mathrm{dC}_{\mathrm{S}}$ at $411 \mathrm{~K}$ from figure 4 where only hardening is observed is plotted against the initial rate of change in lattice parameter of $\mathrm{Mo} d a / \mathrm{dC}_{\mathrm{S}}$ from figure 7 . The data for $\mathrm{W}, \mathrm{Ta}$, and $\mathrm{Hf}$ additions suggest that the atomic size misfit parameter may be important in controlling hardness in these systems. However, additions of Re, Os, Ir, and Pt cannot be related to the atomic size misfit parameter. A similar plot is shown in figure 8(b) for data at $77 \mathrm{~K}$, where the initial softening rate $\mathrm{dH} / \mathrm{dC}_{\mathrm{S}}$ is shown for $\mathrm{Re}, \mathrm{Os}$, Ir, and Pt additions along with the hardening rate for $\mathrm{Hf}, \mathrm{Ta}$, and $\mathrm{W}$ additions. Again hardness of binary Mo-Hf, Mo-Ta, and Mo- W alloys can be correlated with the atomic size misfit parameter $\mathrm{da} / \mathrm{dC}_{\mathrm{S}}$. Rate of alloy softening cannot be correlated with atomic size misfit for binary Mo-Re, Mo-Os, Mo-Ir, and Mo-Pt alloys.

Data for rate of change in moduli are not available for the binary alloys, and therefore, the correlation with rate of hardening or softening cannot be examined.

\section{Electron Concentration}

A further comparison is made of the hardness behavior of the binary Mo alloys for data determined at $77 \mathrm{~K}$. In figure 9 (a) data are compared for those alloys producing hardening of Mo, while in figure 9 (b) a comparison is made of data for alloying elements that initially produce softening of Mo. The increases in hardness at a particular solute content are noted to vary remarkably. For example, at a solute content of 8 atomic percent for solute elements producing only hardening of Mo (fig. 9(a)) approximate increases in VHN of 30,80 , and 160 result for alloy additions of $\mathrm{W}, \mathrm{Ta}$, and Hf, respectively. In contrast, at similar solute contents for those elements producing an initial softening of Mo (fig. 9(b)) increases in VHN of approximately 160, 380, and 620 result for additions of Os, Ir, and Pt, while Re additions at the 8 atomic percent content produce a decrease in VHN of approximately 75, as shown in figure 9(b).

As mentioned previously in the section EXPERIMENTAL PROGRAM, solute content was selected to give alloys having equivalent values of electron-atom ratio e/a. The e/a of a binary Mo alloy can be represented by 


$$
\left(\frac{\mathrm{e}}{\mathrm{a}}\right)_{\text {alloy }}=\mathrm{C}_{\mathrm{Mo}}\left(\frac{\mathrm{e}}{\mathrm{a}}\right)_{\mathrm{Mo}}+\mathrm{C}_{\mathrm{S}}\left(\frac{\mathrm{e}}{\mathrm{a}}\right)_{\mathrm{S}}
$$

where $C_{M o}$ and $C_{S}$ are the atom fraction of Mo and solute, respectively. Equation (1) can be written as

$$
\left(\frac{e}{a}\right)_{\text {alloy }}=\left(1-C_{S}\right)\left(\frac{e}{a}\right)_{\text {Mo }}+C_{S}\left(\frac{e}{a}\right)_{S}
$$

or

$$
\left(\frac{\mathrm{e}}{\mathrm{a}}\right)_{\text {alloy }}=\left(\frac{\mathrm{e}}{\mathrm{a}}\right)_{\mathrm{Mo}}+\mathrm{C}_{\mathrm{S}}\left[\left(\frac{\mathrm{e}}{\mathrm{a}}\right)_{\mathrm{S}}-\left(\frac{\mathrm{e}}{\mathrm{a}}\right)_{\mathrm{Mo}}\right]
$$

where $(\mathrm{e} / \mathrm{a})_{\mathrm{S}}-(\mathrm{e} / \mathrm{a})_{\mathrm{Mo}}$ is equal to the difference in number of $\mathrm{s}+\mathrm{d}$ electrons $\Delta \mathrm{V}$.

The change in electron concentration upon alloying Mo with elements from the sixth period is given by

$$
\Delta \frac{\mathrm{e}}{\mathrm{a}}=\left(\frac{\mathrm{e}}{\mathrm{a}}\right)_{\text {alloy }}-\left(\frac{\mathrm{e}}{\mathrm{a}}\right)_{\mathrm{Mo}}=\mathrm{C}_{\mathrm{S}} \Delta \mathrm{V}
$$

Values of number of $\mathrm{s}+\mathrm{d}$ electrons are shown in figure 1.

The effect of difference in electron concentration on hardness for the binary Mo alloys is shown in figure 10 for data determined at $77 \mathrm{~K}$. Data for Mo-W alloys are excluded from this plot since $\Delta \mathrm{V}=0$. It is interesting to note in figure 10 that a smooth curve can be drawn through hardness values for dilute Mo-Hf and Mo-Ta alloys, where hardening is observed, and through hardness values for dilute Mo-Re, Mo-Os, Mo-Ir, and Mo-Pt alloys, where alloys softening is observed. The authors (ref. 1) showed that alloy hardening in group VIA - Re alloys was proportional to the square root of solute content (parabolic hardening). Figure 11 shows the variation of hardness with the square root of solute content and the difference in electron concentration, where the parameter $\Omega$ is

$$
\Omega \equiv \mathrm{C}_{\mathrm{S}}^{1 / 2} \Delta \mathrm{V}
$$

It can be seen in figure 11(a) that the alloy hardening data at $77 \mathrm{~K}$ for Mo- Hf and Mo- Ta alloys and alloy softening data for Mo-Re, Mo-Os, Mo-Ir, and Mo-Pt alloys fit reasonably well to a least-squares line drawn through the data. A least-squares line drawn through the alloy hardening data for Mo-Re, Mo-Os, Mo-Ir, and Mo- Pt alloys also 
yields a reasonable fit of the data with the exception of the two most concentrated Mo-Re alloys. Figures $11(b),(c)$, and (d) show that this type of correlation of the data is satisfactory at temperatures of 188,300 , and $411 \mathrm{~K}$. It should be noted in figure 11 that the slopes of the two lines are approaching each other as temperature increases, implying that hardness can be correlated with $|\Delta \mathrm{V}|$ above the temperature where alloy softening disappears.

From the correlation shown in figure 11 it is concluded that the hardness or strength of binary alloys of Mo with sixth period elements Hf through Pt can best be correlated with electron concentration. Even though the initial rate of hardening in Mo- Hf and Mo-Ta alloys could be correlated with atomic size factor, it appears that electron concentration plays a more dominant role over the entire range of compositions investigated here.

Comparison of our previous work on group VIA - Re alloys (ref. 1) reveals that a correlation of hardness for these alloys is also consistent with the present relation between hardness and $\Omega$, since for $\mathrm{Cr}$, Mo, or W alloyed with $\mathrm{Re}, \Delta \mathrm{V}$ is constant. A least-squares fit of hardness data in the previous study indicated hardness could be expressed in proportion to Re content or to the square root of Re content. Based on the present results it appears that the square root of solute content is preferred. It would appear from these two studies that the correlation between electron concentration and hardness or strength may be applicable to other body-centered cubic transition metal alloys.

Examination of figure 11 reveals that the hardness minimum occurs at lower values of $\Omega$ with increasing temperature. Figure 12 shows that $\Omega_{\text {min }}$, the value of $\Omega$ at the hardness minimum, decreases linearly with increasing temperature. A least-squares line through the data in figure 12 extrapolates to a temperature of $487 \mathrm{~K}\left(0.169 \mathrm{~T}_{\mathrm{m}}\right)$. Above this temperature alloy softening would not be expected in the binary Mo - sixthperiod-element alloys. This is in good agreement with a temperature of $461 \mathrm{~K}(0.16 \mathrm{~T} \mathrm{~m})$ for Mo-Re alloys determined by averaging the data for group VIA - Re alloys (ref. 1). The line in figure 12 extrapolates to $\Omega_{\min }=3.17$ (at. \%) ${ }^{1 / 2}$ at $0 \mathrm{~K}$, from which the maximum amount of solute that can be added to produce alloy softening can be determined from the relation $\Omega_{\min }=\mathrm{C}_{\mathrm{S}}^{1 / 2} \Delta \mathrm{V}=3.17$ (at. \%) ${ }^{1 / 2}$ at $0 \mathrm{~K}$. The amounts of Re, Os, Ir, and Pt expected at the hardness minimum in Mo would be 10, 2.5, 1.1, and 0.6 atomic percent, respectively.

\section{CONTROLLING MECHANISM}

The correlation of hardness with electron concentration for the alloys investigated points to an intrinsic property of the transition metal alloys being responsible for the 
alloy softening and hardening that has been observed in this study. The lack of softening in Mo-Hf and Ta alloys suggests that scavenging, even though it may occur in these alloys, is not important in controlling alloy softening in these materials. Also, failure to correlate hardening or softening rates with atomic size factor alone, especially where the greatest rates of hardening and softening were observed in Mo- Pt alloys without a change in lattice parameter, precludes the atomic size factor being a controlling mechanism. As pointed out previously by the authors (ref. 1) and by Arsenault (ref. 23), alloying Mo with elements having a greater number of $s+d$ electrons can lead to a reduction in the Peierls stress as a result of reducing the directionality of the electron bonding. A lowering of the Peierls stress has been proposed by several investigators to be responsible for alloy softening (refs. 1, 2, 3, 18, and 22).

The abrupt change to alloy hardening at $\Omega=2.64$ (at. $\%)^{1 / 2}$ at $77 \mathrm{~K}$ for the binary Mo alloys and at decreasing $\Omega$ at higher temperatures is of primary importance in determining the mechanism of alloy softening and hardening in these alloys. Some insight into the change in softening to hardening may be gained from a study of the magnetic susceptibility of these alloys, which gives some information as to the electron structure. Jones and McQuillan (ref. 24) and Booth (ref. 25), in studying the magnetic susceptibility of Mo-Re alloys, showed that, instead of the expected increase in magnetic susceptibility with increase in Re content within the entire solubility range, a maximum was observed. Neither Jones and McQuillan nor Booth correlated this anomaly with the density-of-states curve, but if the observation is real and characteristic of the other binary Mo alloys under investigation here, measurements of this type may help lead to an understanding of the role that electron structure plays in the mechanical behavior of the transition metals and alloys.

\section{CONCLUSIONS}

Based on a hardness study of binary alloys of molybdenum (Mo) with hafnium (Hf), tantalum (Ta), tungsten (W), rhenium (Re), osmium (Os), iridium (Ir), and platinum (Pt), the following conclusions are drawn:

1. Hardness of the alloys investigated can be correlated with electron concentration of the alloys.

2. Alloy softening is produced in Mo by those elements having an excess of $s+d$ electrons compared to Mo. Elements having fewer $s+d$ electrons than Mo or an equal number of $\mathbf{s}+\mathbf{d}$ electrons do not produce alloy softening.

3. Alloy hardening of Mo- Hf and Mo-Ta alloys and alloy softening of Mo-Re, Mo-Os, Mo-Ir, and Mo-Pt alloys can be correlated with the square root of solute content and difference in electron concentration due to addition of the solute element. Alloy hardening in Mo-Re, Mo-Os, Mo- Ir, and Mo- Pt alloys obeys a similar correlation. 
4. Scavenging of interstitials by solute elements does not appear responsible for alloy softening in Mo - sixth-period-transition-metal alloys.

5. Atomic size factor may play a minor role in hardness behavior of Mo-Hf, Mo-Ta, and Mo-W alloys, but cannot be correlated with hardness behavior of Mo-Re, Mo-Os, Mo-Ir, and Mo-Pt alloys.

Lewis Research Center,

National Aeronautics and Space Administration, Cleveland, Ohio, March 28, 1972,

114-03.

\section{REFERENCES}

1. Stephens, J. R.; and Witzke, W. R.: Alloy Softening in Group VIA Metals Alloyed with Rhenium. J. Less-Common Metals, vol. 23, 1971, pp. 325-342.

2. Anon.: Alloy Softening I, II, and III. Conference Abstracts from the Joint Fall Meeting of the AIME, ASM, ASN, and MPIF, Detroit, Mich., Oct. 18-21, 1971.

3. Hasson, D. F.; and Arsenault, R. J.: Solid Solution Weakening of B.C.C. Solid Solutions. Proceedings of the Second International Conference on the Strength of Metals and Alloys. Vol. 1. ASM, 1970, pp. 267-271.

4. Arsenault, R. J.: Solid Solution Strengthening and Weakening of B. C. C. Solid Solutions. Acta Met., vol. 17, no. 10, Oct. 1969, pp. 1291-1297.

5. Sagues, A. A.; and Gibala, R.: Substitutional-Interstitial Solute Interactions in Ta-Re-N Solutions. Scripta Met., vol. 5, no. 8, Aug. 1971, pp. 689-693.

6. Elliott, Rodney P.: Constitution of Binary Alloys, First Supplement. McGraw-Hill Book Co., Inc., 1965.

7. Hansen, Max; and Anderko, Kurt: Constitution of Binary Alloys. Second ed., McGraw-Hill Book Co., Inc., 1958.

8. Shunk, Francis A.: Constitution of Binary Alloys, Second Supplement. McGraw-Hill Book Co., Inc., 1969.

9. Ocken, H.; and Van Vucht, J. H. N.: Phase Equilibria and Superconductivity in the Molybdenum-Platinum System. J. Less-Common Metals, vol. 15, 1968, pp. 193199. 
10. Schmidt, Frank F.; Ingram, Albert G.; Klopp, William D.; Bartlett, Edwin S. ; and Ogden, Horace R.: Investigation of Tantalum and Its Alloys. Battelle Memorial Inst. (ASD-TDR-62-594), Oct. 1962.

11. Schmidt, Frank F.; Bartlett, Edwin S.; and Ogden, Horace R.: Investigation of Tantalum and Its Alloys. Battelle Memorial Inst. (ASD-TDR-62-594, Pt. 2), May 1963.

12. Myers, Rupert H.: Some Properties of Tantalum-Rich Alloys with Wolfram and Molybdenum. Metallurgia, vol. 42, no. 248, June 1950, pp. 3-9.

13. Jaffee, R. I.; Sims, C. T.; and Harwood, J. J.: The Effect of Rhenium on the Fabricability and Ductility of Molybdenum and Tungsten. Plansee Proceedings1958. F. Benesovsky, ed., Pergamon Press, 1959, pp. 380-411.

14. Dahl, J.; and Semchyshen, M.: Characterization of the Hexagonal - Close- Packed Intermetallic Compound from the Mo- Rh, Mo-Ir, and Mo-Pt Systems. Climax Molybdenum Co. of Michigan, Jan. 1, 1969. (Available from DDC as AD849163L.)

15. Manzone, M. G. ; and Briggs, J. Z.: Mo, Less-Common Alloys of Molybdenum. Climax Molybdenum Co., 1962.

16. Wise, E. M.; and Vines, R. F.: Effect of Cold-Work Upon Hardness and Recrystallization Behavior of Pure Platinum. Trans. AIME, vol. 137, 1940, pp. 464473.

17. Schick, H. L., ed.: Thermodynamics of Certain Refractory Compounds. Vol. 2. Academic Press, 1966.

18. Fleischer, R. L.: Substitutional Solution Hardening. Acta Met., vol. 11, no. 3, Mar. 1963, pp. 203-209.

19. Mitchell, T. E.; and Raffo, P. L.: Mechanical Properties of Some Tantalum Alloys. Can. J. Phys., vol. 45, no. 2, pt. 3, Feb. 1967, pp. 1047-1062.

20. Teatum, E. T.; Gschneidner, K. A., Jr.; and Waber, J. T.: Compilation of Calculated Data Useful in Predicting Metallurgical Behavior of the Elements in Binary Alloy Systems. Rep. LA-4003, Los Alamos Scientific Lab., Dec. 24, 1968.

21. Pearson, W. B. : A Handbook of Lattice Spacings and Structures of Metals and Alloys. Vol. 1. Pergamon Press, 1958.

22. Pearson, W. B. : A Handbook of Lattice Spacings and Structures of Metals and Alloys. Vol. 2. Pergamon Press, 1967. 
23. Arsenault, R. J.: The Double-Kink Model for Low-Temperature Deformation of B. C.C. Metals and Solid Solutions. Acta Met., vol. 15, no. 3, Mar. 1967, pp. 501-511.

24. Jones, D. W.; and McQuillan, A. D.: Magnetic Susceptibility and Hydrogen Affinity of B.C.C. Alloys of Nb-Mo, Nb-Re, and Mo-Re. J. Phys. Chem. Solids, vol. 23, 1962, pp. 1441-1447.

25. Booth, J. G. : Effect of Electron Concentration on the Properties of Alloys of Refractory Metals. Battelle Memorial Inst., Oct. 30, 1964. (Available from DDC as AD-607799.) 
TABLE I. - CHEMICAL ANALYSIS, ELECTRON-ATOM RATIO, AND VALUES OF $\Omega$ FOR BINARY MOLYBDENUM ALLOYS

\begin{tabular}{|c|c|c|c|c|c|c|c|}
\hline \multicolumn{2}{|c|}{$\begin{array}{l}\text { Solute content, } \\
\text { at. } \%\end{array}$} & \multicolumn{4}{|c|}{$\begin{array}{c}\text { Interstitial content, } \\
\text { ppm }\end{array}$} & \multirow{2}{*}{$\begin{array}{c}\text { Electron- } \\
\text { atom } \\
\text { ratio, } \\
\mathrm{e} / \mathrm{a}\end{array}$} & \multirow[t]{2}{*}{$\Omega=C_{S}^{1 / 2} \Delta V$} \\
\hline Nominal & Analyzed & $\mathrm{C}$ & $\mathrm{H}$ & $\mathrm{N}$ & $\mathrm{O}$ & & \\
\hline \multicolumn{8}{|c|}{ Mo- Hf } \\
\hline 1.0 & 0.92 & -- & --- & $\ldots$ & -- & 5.982 & -1.92 \\
\hline 2.5 & 2.7 & 16 & 2.0 & 2.1 & 29 & 5.946 & -3.29 \\
\hline 4.0 & 3.9 & -- & -- & --- & -- & 5.922 & -3.95 \\
\hline 5.0 & 4.8 & -- & -- & --- & -- & 5.904 & -4.38 \\
\hline 10.0 & 9.9 & 21 & 2.2 & 4.2 & 31 & 5.802 & -6.29 \\
\hline 16.0 & 15.9 & -- & --- & $-\cdots$ & -- & 5.682 & -7.98 \\
\hline \multicolumn{8}{|c|}{ Mo- Ta } \\
\hline 0.4 & 0.23 & -- & --- & --- & -- & 5.998 & -0.45 \\
\hline 2.0 & 2.2 & 13 & 2.5 & 3.4 & 16 & 5.978 & -1.48 \\
\hline 5.0 & 4.9 & -- & --- & --- & -- & 5.951 & -2.21 \\
\hline 8.0 & 7.9 & -- & --- & --- & -- & 5.921 & -2.81 \\
\hline 20.0 & 17.1 & 12 & 2.5 & 4.9 & 40 & 5.829 & -4.14 \\
\hline 32.0 & 25.3 & -- & -- & --- & -- & 5.747 & -5.03 \\
\hline 40.0 & 38.2 & -- & --- & --- & - & 5.618 & -6.18 \\
\hline 60.0 & 59.3 & -- & -- & --- & -- & 5.407 & -7.71 \\
\hline 80.0 & 81.5 & -- & -- & -- & - & 5.185 & -9.04 \\
\hline \multicolumn{8}{|c|}{ Mo-W } \\
\hline 2.0 & 1.1 & -- & --- & --- & - & 6.00 & 0 \\
\hline 5.0 & 3.4 & 25 & 2.7 & 4.0 & 24 & ---- & $-\cdots-$ \\
\hline 8.0 & 5.5 & -- & --- & --- & -- & ---- & $-\cdots-$ \\
\hline 10.0 & 12.1 & -- & --- & --- & - & ---- & $-\cdots$ \\
\hline 20.0 & 18.8 & 8 & 1.4 & 1.6 & 17 & ---- & $\ldots-$ \\
\hline 32.0 & 37.2 & -- & --- & -- & -- & ---- & $-\cdots$ \\
\hline 60.0 & 58.3 & -- & -- & --- & -- & ---- & $-\cdots$ \\
\hline 80.0 & 82.4 & -- & --- & -- & -- & ---- & ---- \\
\hline
\end{tabular}


TABLE I. - Concluded. CHEMICAL ANALYSIS, ELECTRON-

RATIO, AND VALUES OF $\Omega$ FOR BINARY

MOLYBDENUM ALLOYS

\begin{tabular}{|c|c|c|c|c|c|c|c|}
\hline \multicolumn{2}{|c|}{$\begin{array}{l}\text { Solute content, } \\
\text { at. } \%\end{array}$} & \multicolumn{4}{|c|}{$\begin{array}{c}\text { Interstitial content, } \\
\text { ppm }\end{array}$} & \multirow{2}{*}{$\begin{array}{c}\text { Electron- } \\
\text { atom } \\
\text { ratio, } \\
\text { e/a }\end{array}$} & \multirow[t]{2}{*}{$\Omega=\mathrm{C}_{\mathrm{S}}^{1 / 2} \Delta \mathrm{V}$} \\
\hline Nominal & Analyzed & $\mathrm{C}$ & $\mathrm{H}$ & $\mathrm{N}$ & 0 & & \\
\hline \multicolumn{8}{|c|}{ Mo-Re } \\
\hline 2.0 & 2.0 & 31 & 2.1 & 4.1 & 24 & 6.020 & 1.41 \\
\hline 5.0 & 5.3 & -- & --- & --- & -- & 6.053 & 2.30 \\
\hline 8.0 & 8.2 & -- & -- & --- & -- & 6.082 & 2.86 \\
\hline 10.0 & 10.2 & - & --- & --- & -- & 6.102 & 3.19 \\
\hline 20.0 & 20.3 & 41 & 1.6 & 6.5 & 29 & 6.203 & 4.51 \\
\hline 32.0 & 32.6 & -- & --- & --- & -- & 6.326 & 5.71 \\
\hline \multicolumn{8}{|c|}{ Mo-Os } \\
\hline 1.0 & 1.11 & -- & -- & --- & -- & 6.022 & 2.10 \\
\hline 1.7 & 1.72 & -- & --- & -- & -- & 6.034 & 2.63 \\
\hline 2.5 & 2.61 & 12 & 1.8 & 2.2 & 20 & 6.052 & 3.24 \\
\hline 4.0 & 3.64 & - & --- & $\ldots$ & -- & 6.073 & 3.82 \\
\hline 5.0 & 5.23 & -- & -- & --- & -- & 6.105 & 4.57 \\
\hline 10.0 & 9.85 & 19 & 3.4 & 3.2 & 20 & 6.197 & 6.28 \\
\hline 16.0 & 15.76 & -- & --- & -- & -- & 6.315 & 7.94 \\
\hline \multicolumn{8}{|c|}{ Mo-Ir } \\
\hline 0.67 & 0.63 & -- & -- & --- & -- & 6.019 & 2.39 \\
\hline 1.10 & 1.12 & - & -- & --- & -- & 6.034 & 3.18 \\
\hline 1.67 & 1.71 & -- & -- & --- & - & 6.051 & 3.92 \\
\hline 2.67 & 2.49 & 16 & 1.1 & 7.7 & 20 & 6.075 & 4.73 \\
\hline 3.30 & 3.31 & -- & --- & -- & - & 6.099 & 5.46 \\
\hline 6.67 & 6.76 & 15 & 3.0 & 3.7 & 41 & 6.203 & 7.80 \\
\hline 10.67 & 10.46 & -- & -- & --- & -- & 6.314 & 9.70 \\
\hline \multicolumn{8}{|c|}{$\mathrm{Mo}-\mathrm{Pt}$} \\
\hline 0.5 & 0.20 & -- &.- & --- & $\ldots$ & 6.008 & 1.79 \\
\hline .75 & .71 & -- & -- & --- & -- & 6.028 & 3.38 \\
\hline 1.0 & 1.2 & -- & $-\cdots$ & --- & -- & 6.048 & 4.38 \\
\hline 2.0 & 2.0 & 14 & 2.3 & 2.3 & 23 & 6.080 & 5.66 \\
\hline 2.5 & 2.5 & -- & -- & --- & - & 6.100 & 6.32 \\
\hline 5.0 & 4.8 & -- &.- &.-- & -- & 6.192 & 8.76 \\
\hline 8.0 & 7.6 & -- & --- & --- & - & 6.304 & 11.03 \\
\hline \multicolumn{8}{|c|}{ Mo } \\
\hline$-\cdots-\infty$ & $\cdots$ & 15 & 1.4 & 3.4 & 20 & 6.000 & 0 \\
\hline
\end{tabular}


TABLE II. - SUMMARY OF HARDNESS DATA FOR BINARY MOLYBDENUM ALLOYS

\begin{tabular}{|c|c|c|c|c|c|c|c|c|c|}
\hline \multirow{3}{*}{$\begin{array}{l}\text { Solute content, } \\
\text { at. } \%\end{array}$} & \multicolumn{4}{|c|}{ Temperature, $\mathrm{K}$} & \multirow{3}{*}{$\begin{array}{c}\text { Solute content, } \\
\text { at. } \%\end{array}$} & \multicolumn{4}{|c|}{ Temperature, $\mathbf{K}$} \\
\hline & 77 & 188 & 300 & 411 & & 77 & 188 & 300 & 411 \\
\hline & \multicolumn{4}{|c|}{ Vickers hardness number, VHN } & & \multicolumn{4}{|c|}{ Vickers hardness number, VHN } \\
\hline \multicolumn{5}{|c|}{ Mo-Hf } & \multicolumn{5}{|c|}{ Mo-Os } \\
\hline 0.92 & 421 & 290 & 190 & 159 & 1.11 & 349 & 237 & 172 & 149 \\
\hline 2.7 & 437 & 312 & 251 & 221 & 1.72 & 335 & 263 & 218 & 185 \\
\hline 3.9 & 455 & 345 & 301 & 266 & 2.61 & 375 & 303 & 250 & 218 \\
\hline 4.8 & 490 & 355 & 318 & 278 & 3.64 & 414 & 346 & 307 & 263 \\
\hline 9.9 & 601 & 494 & 450 & 392 & 5.23 & 452 & 370 & 318 & 297 \\
\hline 15.9 & 689 & 624 & 576 & 567 & 9.85 & 600 & 524 & 461 & 407 \\
\hline \multicolumn{5}{|c|}{ Mo- Ta } & 15.76 & 716 & 615 & 555 & 486 \\
\hline & 414 & 280 & 175 & 104 & \multicolumn{5}{|c|}{ Mo-Ir } \\
\hline 2.2 & 418 & $\begin{array}{l}280 \\
299\end{array}$ & 186 & 127 & 0.63 & 350 & 267 & 212 & 184 \\
\hline 4.9 & 443 & 333 & 216 & 173 & 1.12 & 405 & 334 & 267 & 232 \\
\hline 7.9 & 472 & 347 & 246 & 214 & 1. 71 & 453 & 376 & 296 & 282 \\
\hline 17.1 & 524 & 416 & 341 & 308 & 2. 49 & 520 & 472 & 389 & 339 \\
\hline 25.3 & 557 & 458 & 397 & 357 & 3.31 & 567 & 512 & 439 & 379 \\
\hline 38.2 & 531 & 485 & 427 & 389 & 6.76 & 730 & 660 & 609 & 549 \\
\hline 59.3 & 513 & 470 & 418 & 400 & 10.46 & 805 & 731 & 711 & 682 \\
\hline 81.5 & 436 & 359 & 309 & 280 & \multicolumn{5}{|c|}{ Mo-Pt } \\
\hline \multicolumn{5}{|c|}{ Mo-W } & & & & & - \\
\hline 1.1 & 401 & 281 & 169 & 110 & $\begin{array}{r}0.20 \\
.71\end{array}$ & $\begin{array}{l}368 \\
401\end{array}$ & $\begin{array}{l}241 \\
330\end{array}$ & $\begin{array}{l}171 \\
254\end{array}$ & $\begin{array}{l}139 \\
227\end{array}$ \\
\hline 3.4 & $\begin{array}{l}401 \\
405\end{array}$ & $\begin{array}{l}201 \\
277\end{array}$ & $\begin{array}{l}109 \\
177\end{array}$ & $\begin{array}{l}110 \\
105\end{array}$ & $\begin{array}{l}.71 \\
1.2\end{array}$ & $\begin{array}{l}401 \\
475\end{array}$ & 412 & $\begin{array}{l}204 \\
315\end{array}$ & $\begin{array}{l}221 \\
295\end{array}$ \\
\hline 5.5 & 423 & 292 & 179 & 117 & 2.0 & 513 & 470 & 393 & 383 \\
\hline 12.1 & 429 & 304 & 186 & 123 & 2.5 & 592 & 544 & 476 & 435 \\
\hline 18.8 & 462 & 325 & 201 & 140 & 4. 8 & 830 & 757 & 674 & 619 \\
\hline 37.2 & 508 & 347 & 228 & 162 & 7.6 & 976 & 949 & 855 & 779 \\
\hline 58.3 & 550 & 414 & 287 & 200 & \multirow{2}{*}{\multicolumn{3}{|c|}{ Mo }} & & \\
\hline 82.4 & 627 & 473 & 343 & 237 & & & & & -- \\
\hline \multicolumn{5}{|c|}{ Mo-Re } & ---- & 391 & 267 & 171 & 105 \\
\hline 2.0 & 375 & 258 & 150 & 113 & & & & & \\
\hline 5.3 & 332 & 226 & 158 & 144 & & & & & \\
\hline 8.2 & 315 & 238 & 189 & 166 & & & & & \\
\hline 10.2 & 336 & 249 & 202 & 179 & & & & & \\
\hline 20.3 & 383 & 326 & 267 & 235 & & & & & \\
\hline 32.6 & 438 & 393 & 332 & 293 & & & & & \\
\hline
\end{tabular}


TABLE III. - STANDARD FREE ENERGIES OF FORMATION AT $2000 \mathrm{~K}$

FOR SOLUTE-INTERSTITIAL REACTIONS

[Data from ref. 17.]

\begin{tabular}{|c|c|c|c|c|c|c|}
\hline \multirow[t]{3}{*}{ Element } & \multicolumn{6}{|c|}{ Interstitial } \\
\hline & \multicolumn{2}{|r|}{$\mathrm{C}$} & \multicolumn{2}{|r|}{0} & \multicolumn{2}{|r|}{$\mathrm{N}$} \\
\hline & Compound & $\begin{array}{c}\text { Free energy of } \\
\text { formation, } \\
\Delta \mathrm{F}_{\mathrm{f}}^{\mathrm{O}} \\
\mathrm{kJ} / \mathrm{g} \text { atom }\end{array}$ & Compound & $\begin{array}{c}\text { Free energy of } \\
\text { formation, } \\
\Delta \mathbf{F}_{\mathrm{f}}^{\mathrm{o}} \\
\mathrm{kJ} / \mathrm{g} \text { atom }\end{array}$ & Compound & $\begin{array}{c}\text { Free energy of } \\
\text { formation, } \\
\Delta \mathrm{F}_{\mathrm{f}}^{\mathrm{O}} \\
\mathrm{kJ} / \mathrm{g} \text { atom }\end{array}$ \\
\hline $\mathrm{Hf}$ & $\mathrm{HfC}$ & -208.8 & $\mathrm{HfO}_{2}$ & -376.6 & HfN & -184.5 \\
\hline $\mathrm{Ta}$ & $\mathrm{Ta}_{2} \mathrm{C}$ & -187.9 & $\mathrm{Ta}_{2} \mathrm{O}_{5}$ & -240.2 & $\mathrm{Ta}_{2} \mathrm{~N}$ & -118.8 \\
\hline w & $\mathrm{w}_{2} \mathrm{C}$ & -116.3 & $\mathrm{wO}_{2}$ & -120.9 & $-\cdots$ & ------ \\
\hline Re & $\ldots-$ & ----- & $\operatorname{ReO}_{(\mathrm{g})}$ & 178.2 & $\cdots$ & ----- \\
\hline Os & $-\cdots-$ & ----- & $\mathrm{OsO}_{3(\mathrm{~g})}$ & -60.2 & - - - & $\ldots$ \\
\hline Ir & $\ldots-$ &.---- & $\operatorname{IrO}_{(\mathrm{g})}$ & 241.4 & $\ldots$ & ----- \\
\hline Pt & $-\cdots-$ & ----- & $\mathrm{PtO}_{(\mathrm{g})}$ & 172.0 & ---- & $\ldots \ldots$ \\
\hline Mo & $\mathrm{Mo}_{2} \mathrm{C}$ & -63.6 & $\mathrm{MoO}_{2}$ & -121.3 & $\ldots-$ & ----- \\
\hline
\end{tabular}

\begin{tabular}{|c|c|c|c|c|c|c|c|}
\hline \multirow[b]{2}{*}{ Fifth period } & \multirow[t]{2}{*}{ Group IV } & \multirow{2}{*}{ Group V } & \multirow{2}{*}{$\begin{array}{c}\text { Group VI } \\
42 \\
\text { Mo } \\
95.94\end{array}$} & \multirow{2}{*}{ Group VII } & \multicolumn{3}{|c|}{ Group VIII } \\
\hline & & & & & & & \\
\hline Sixth period & $\begin{array}{c}72 \\
\mathrm{Hf} \\
178.49\end{array}$ & $\begin{array}{c}73 \\
\mathrm{Ta} \\
180.94\end{array}$ & $\begin{array}{c}74 \\
W \\
183.85\end{array}$ & $\begin{array}{c}75 \\
\mathrm{Re} \\
186.2\end{array}$ & $\begin{array}{c}76 \\
\text { Os } \\
190.2\end{array}$ & $\begin{array}{l}77 \\
\text { Ir } \\
192.2\end{array}$ & $\begin{array}{c}78 \\
\mathrm{Pt} \\
195.09\end{array}$ \\
\hline $\begin{array}{l}\text { Number of } s \text { and } \\
d \text { electrons }\end{array}$ & 4 & 5 & 6 & 7 & 8 & 9 & 10 \\
\hline
\end{tabular}

Figure 1. - Partial periodic table showing solute elements alloyed with molybdenum for this investigation. 

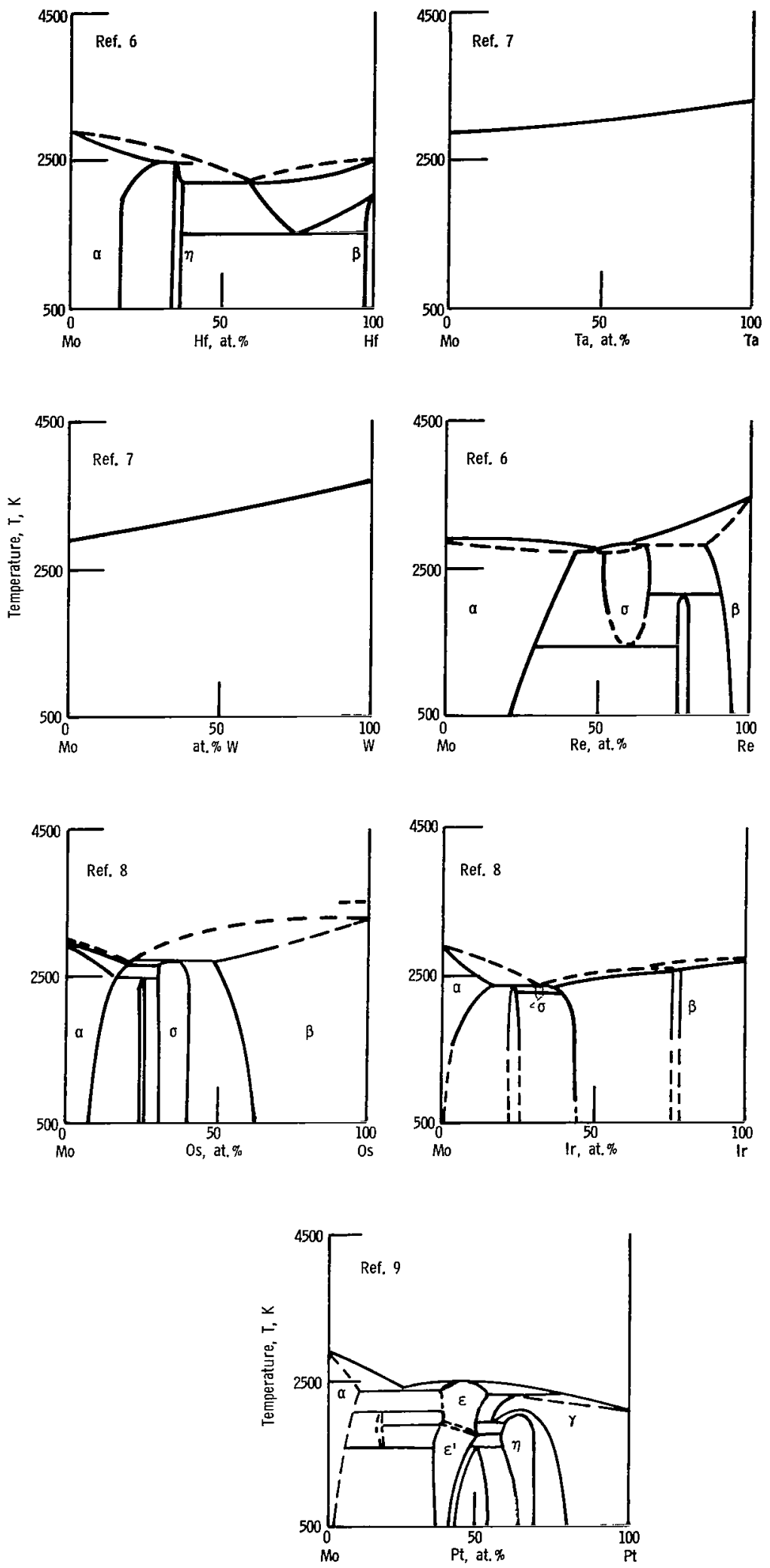

Figure 2. Equilibrium diagrams for binary molybdenum alloy systems under investigation.

18

- 


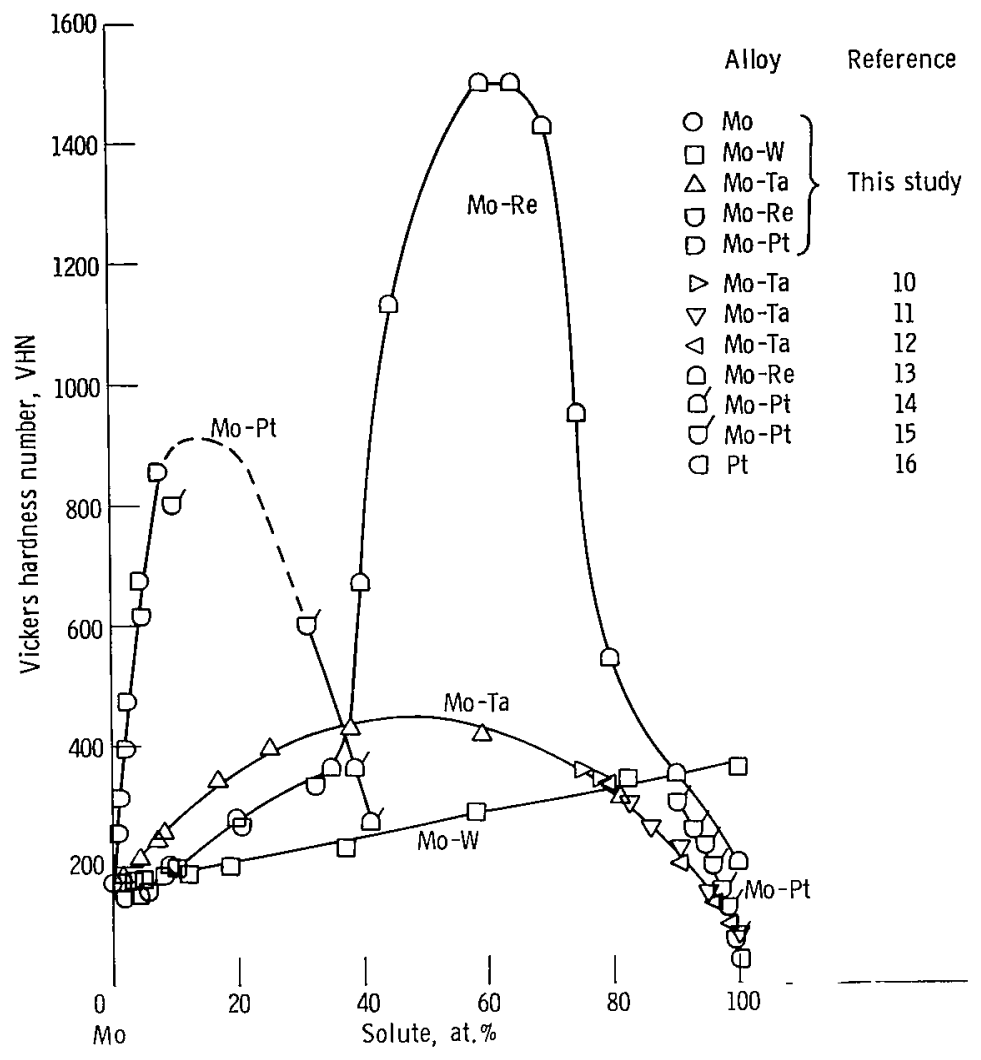

Figure 3. - Hardness behavior at $300 \mathrm{~K}$ in Mo-W, Mo-Ta, Mo-Re, and Mo-Pt alloy systems. 


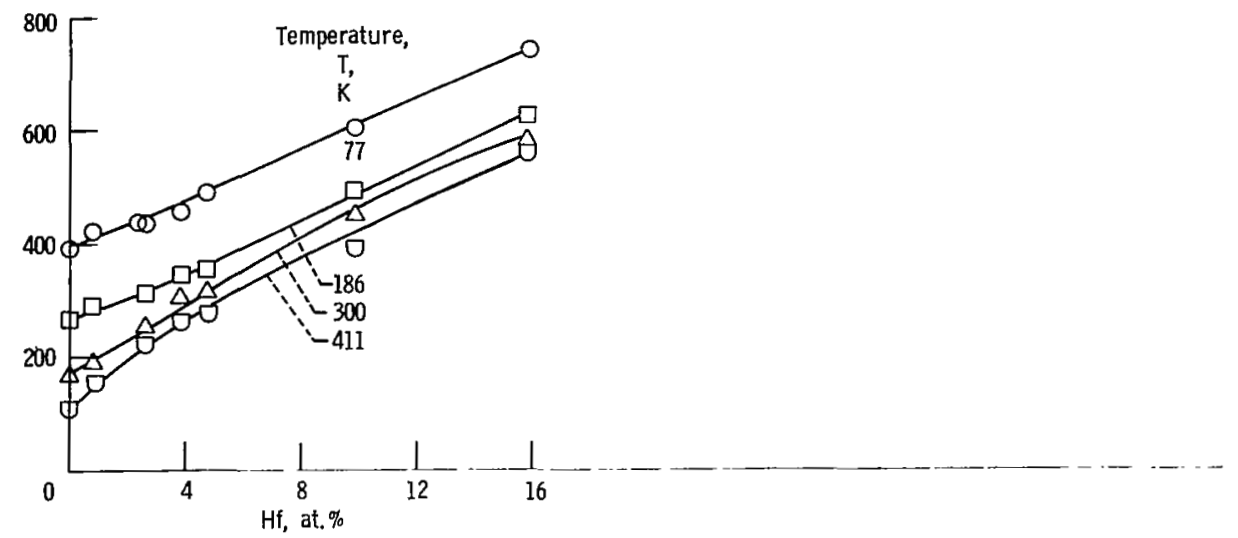

(a) Mo-Hf alloys.

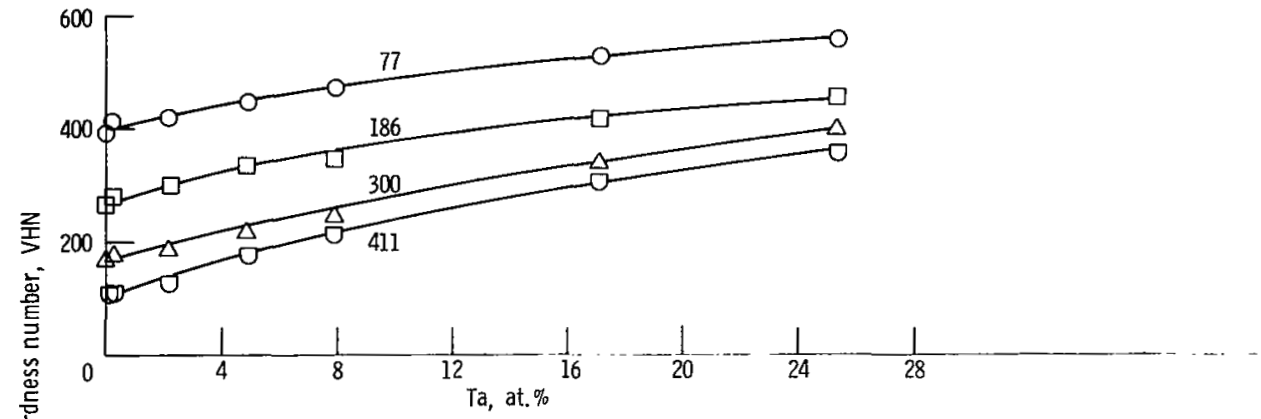

(b) Mo-Ta ailoys.

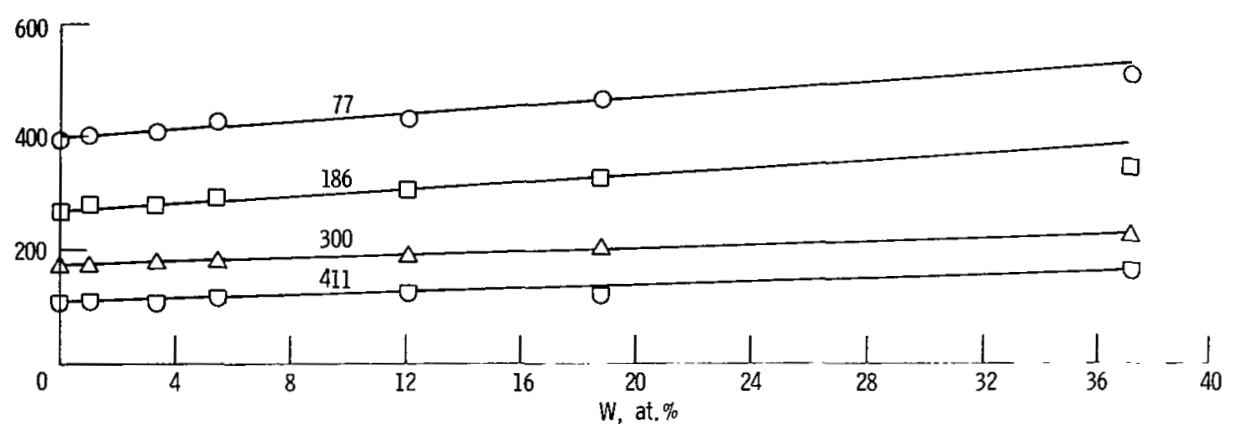

(c) Mo-W alloys.

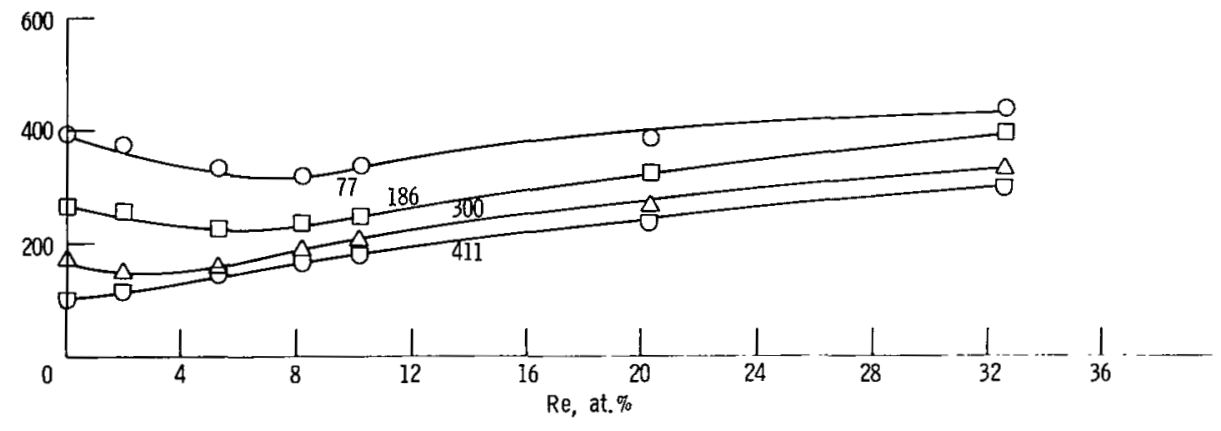

(d) Mo-Re alloys.

Figure 4. - Effect of solute content on hardness of Mo. 


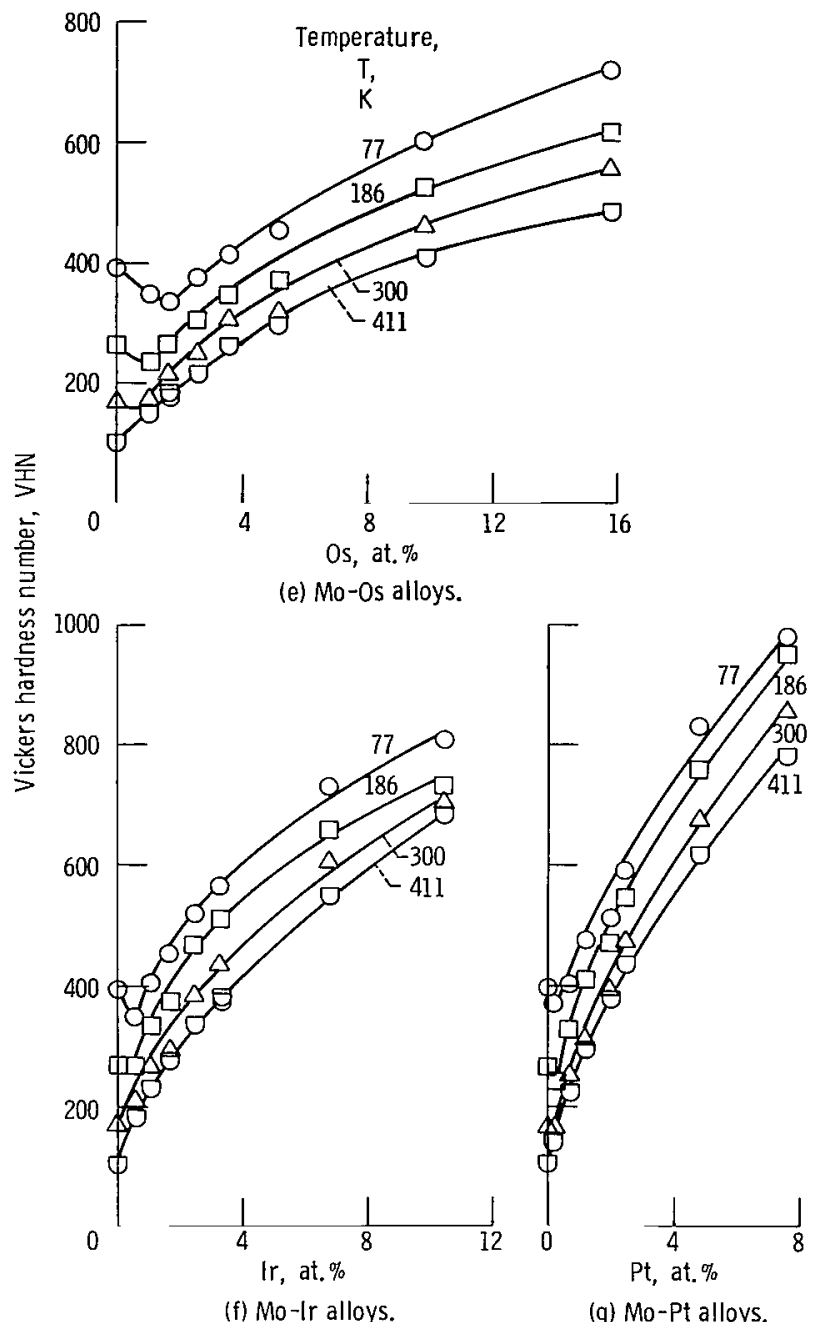

Figure 4. - Concluded. 


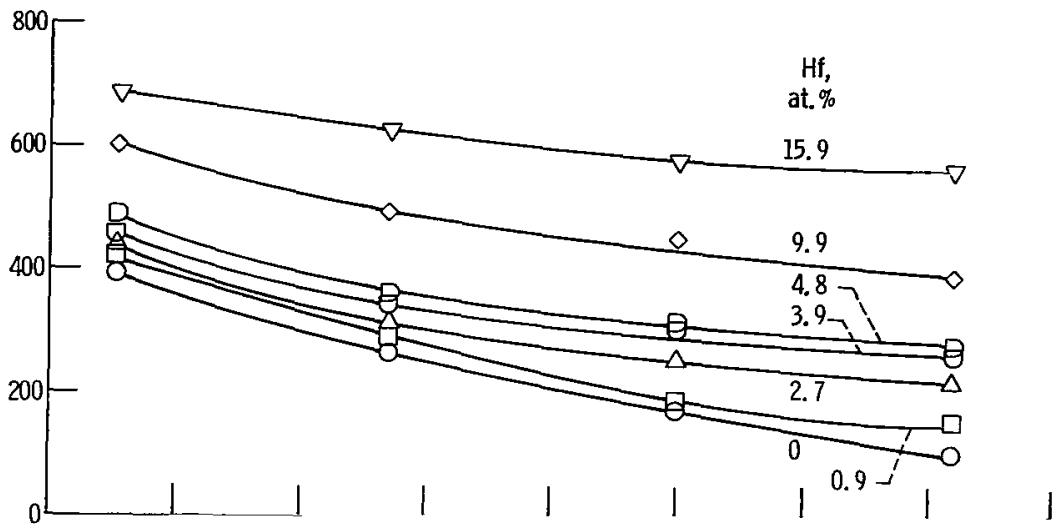

(a) Mo-Hf alloys.

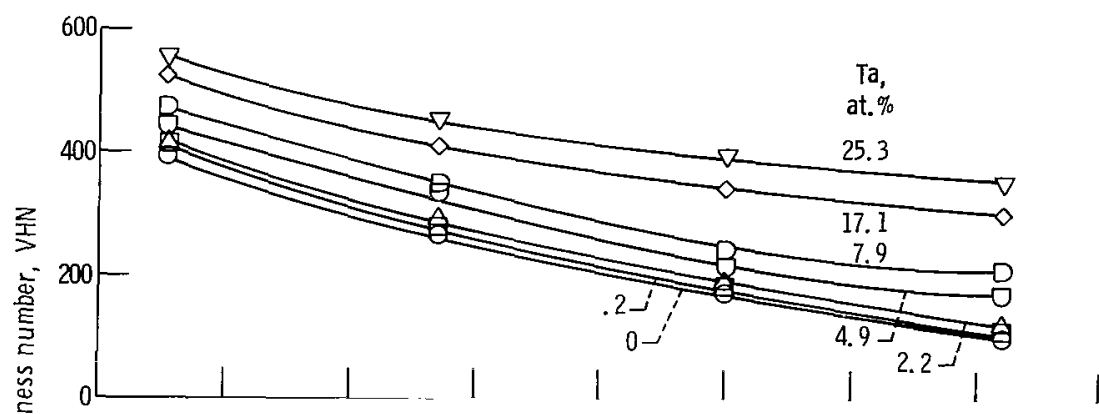

(b) Mo-Ta alloys.

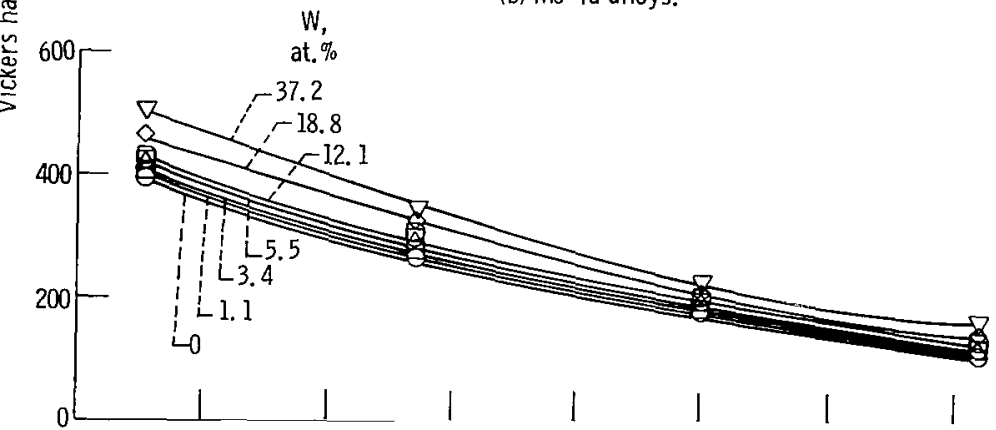

(c) Mo-W alloys.

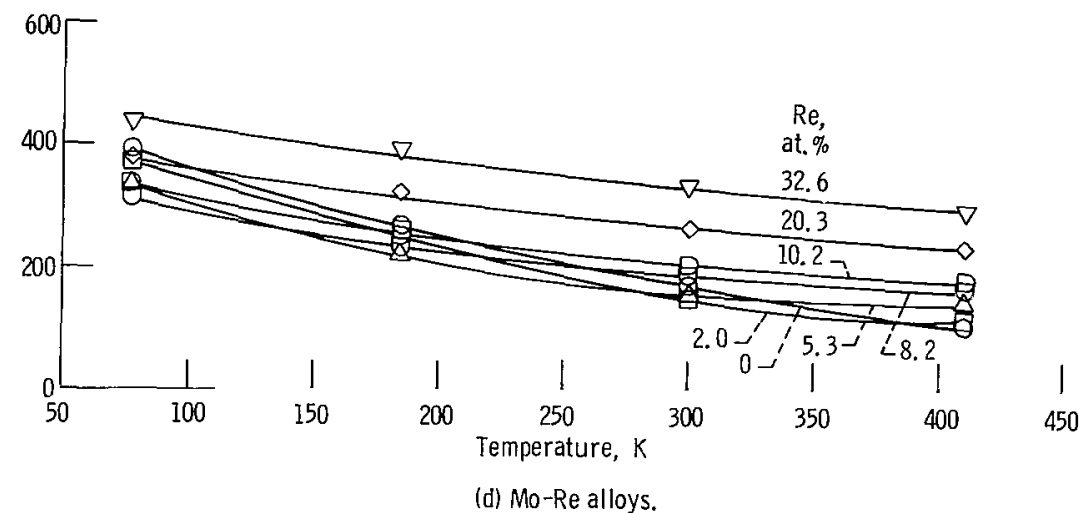

Figure 5. - Effect of temperature on hardness of binary Mo alloys. 


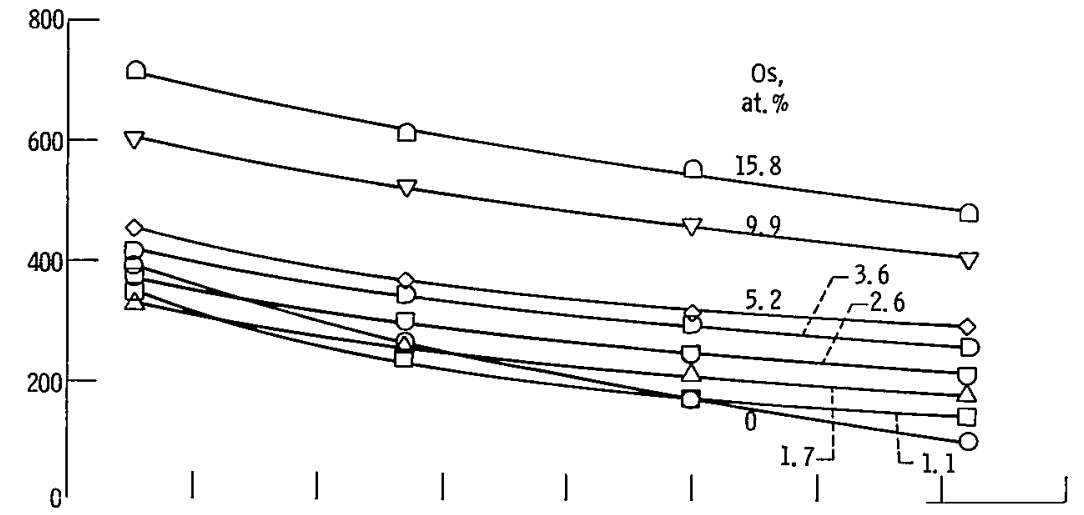

(e) Mo-Os alioys.

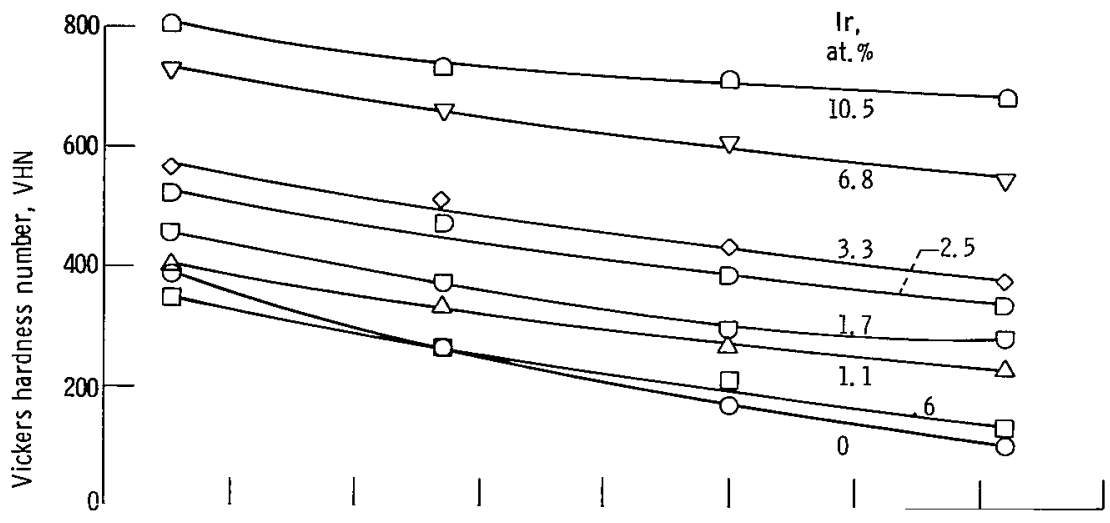

(f) Mo-Ir alloys.

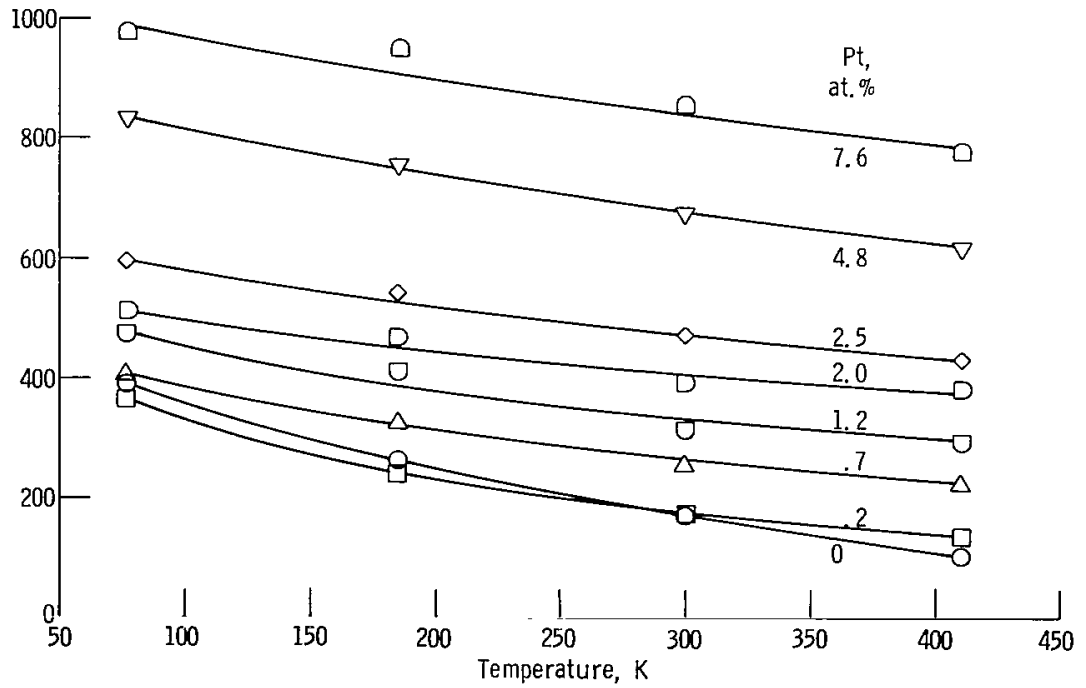

(g) Mo-Pt alloys.

Figure 5. - Concluded. 


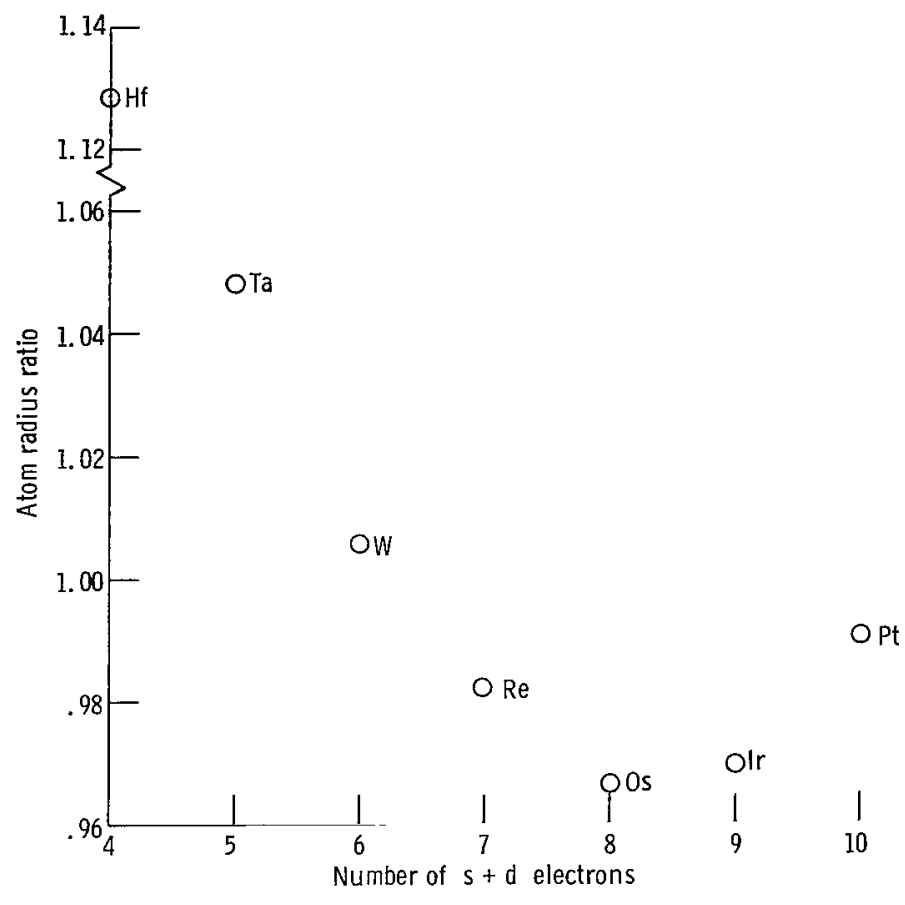

Figure 6. - Comparison of calculated solute-solvent atom radius ratios for binary Mo alloys (ref. 20).

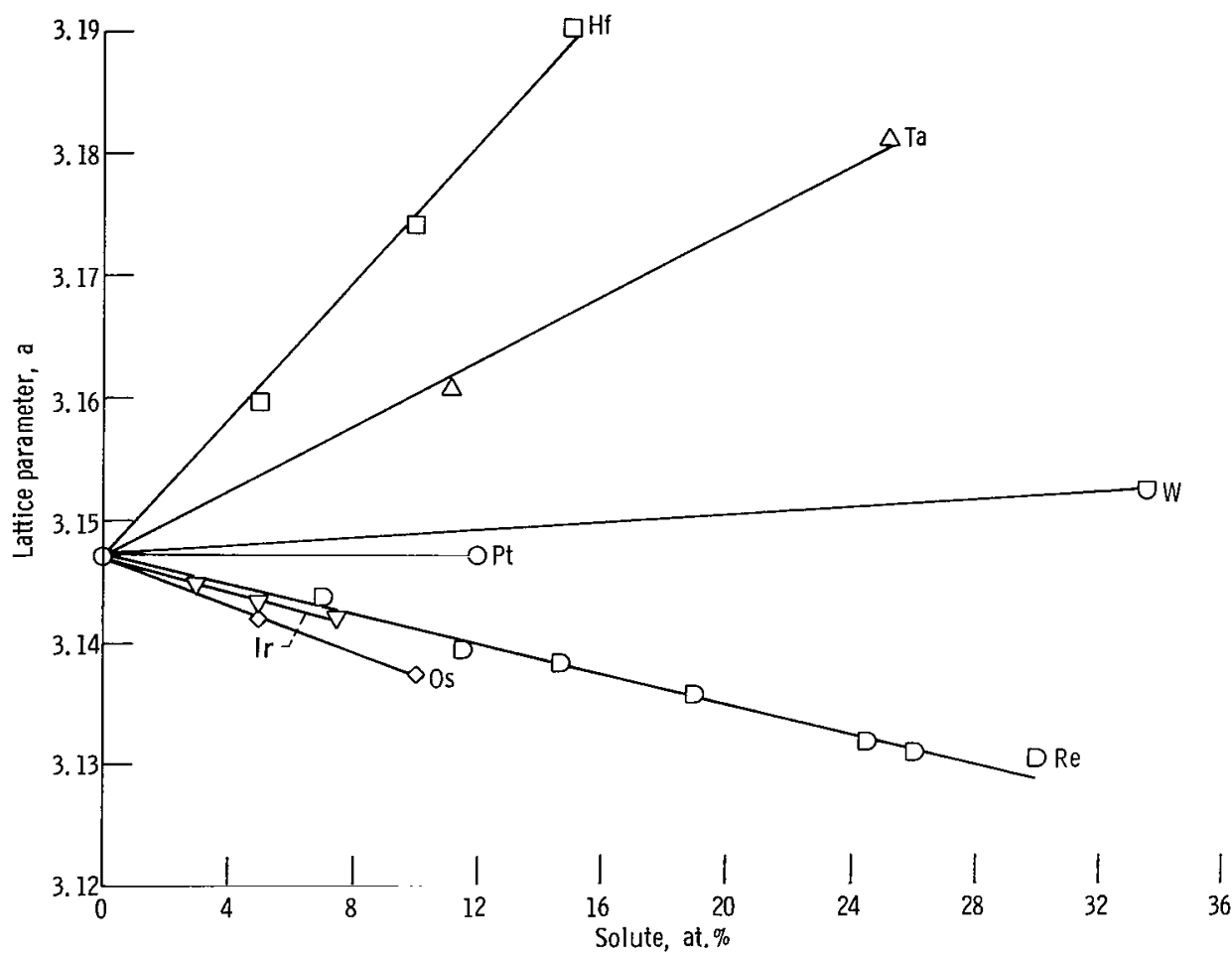

Figure 7. - Lattice parameters of binary Mo alloys as function of solute content (refs. 9, 21, and 22). 


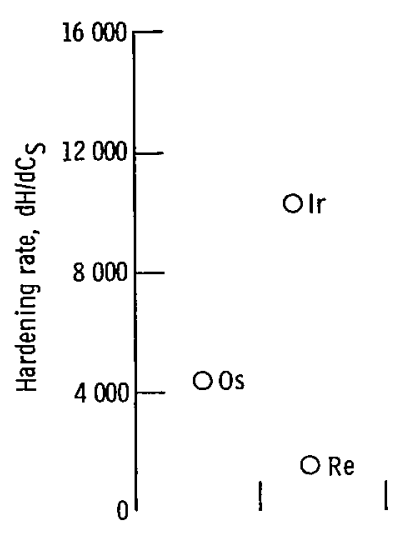

OPt

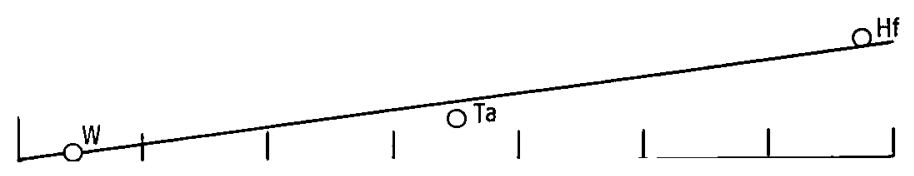

(a) $411 \mathrm{~K}$.
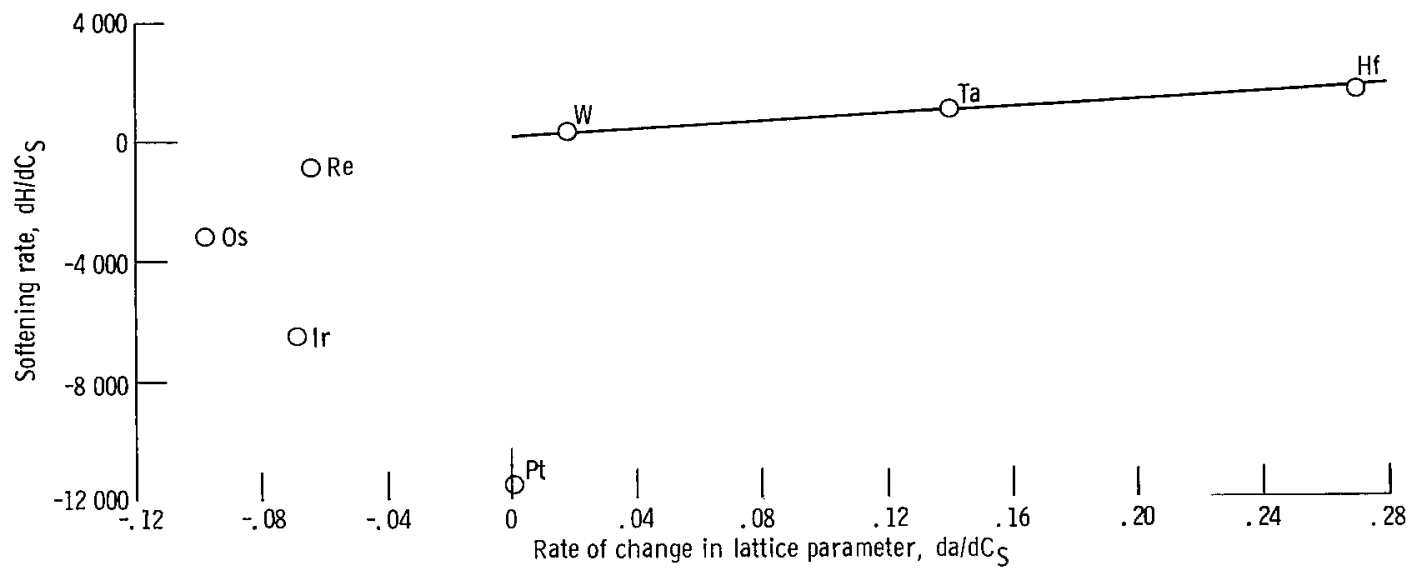

(b) $77 \mathrm{~K}$.

Figure 8. - Effect of atomic size factor on hardening and softening rates in binary Mo alloys. 


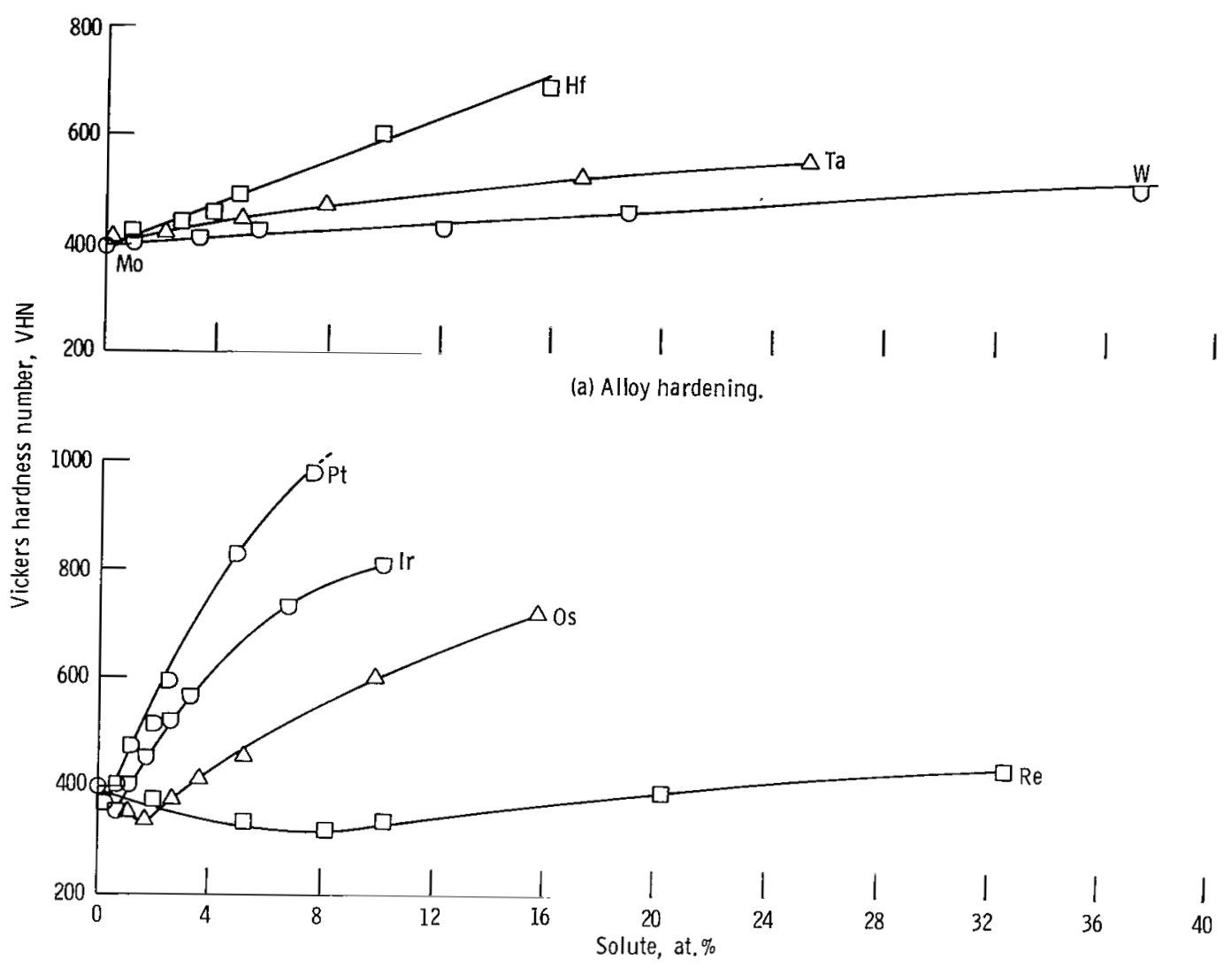

(b) Alloy softening and alloy hardening.

Figure 9. - Comparison of hardness behavior of binary Mo alloys at $77 \mathrm{~K}$.

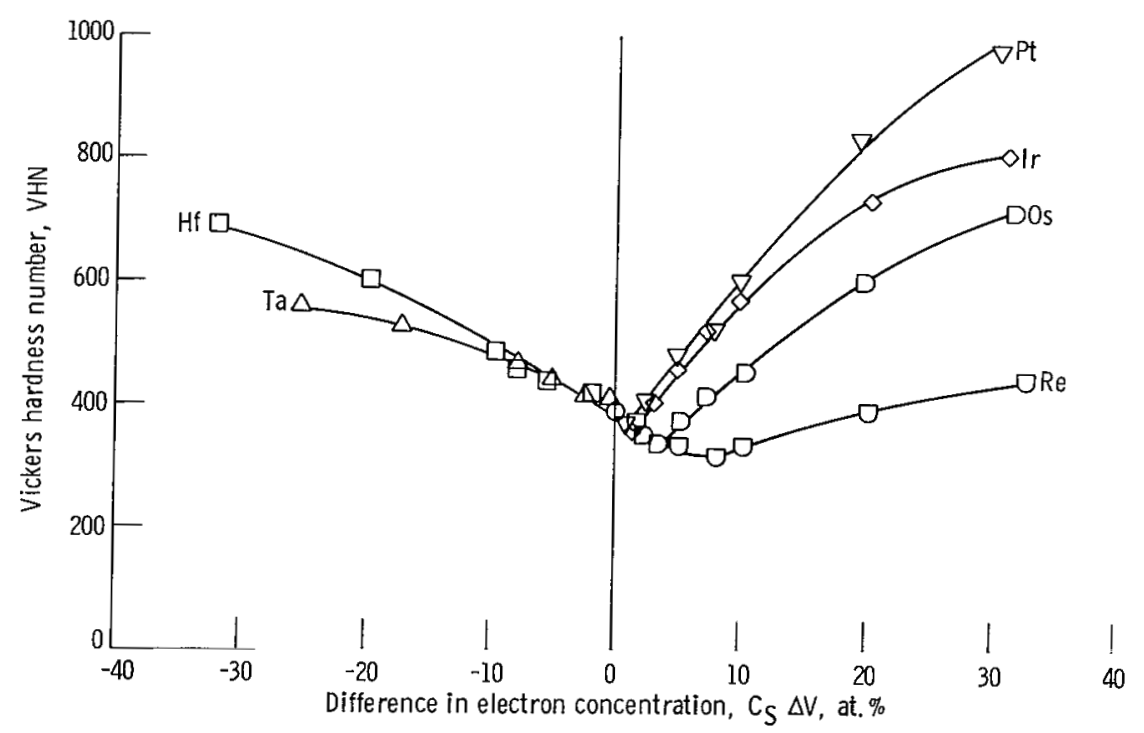

Figure 10. - Effect of solute content and difference in electron concentration on hardness of binary Mo alloys at $77 \mathrm{~K}$. 


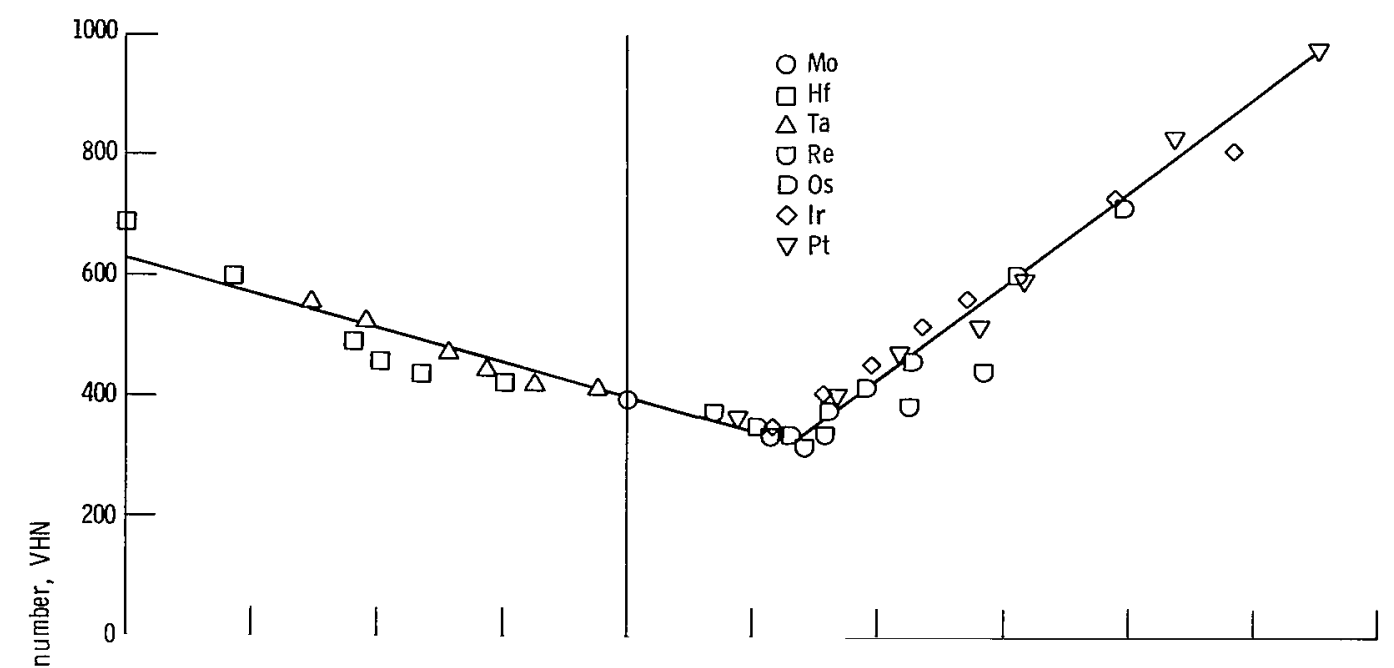

(a) $77 \mathrm{~K}$.

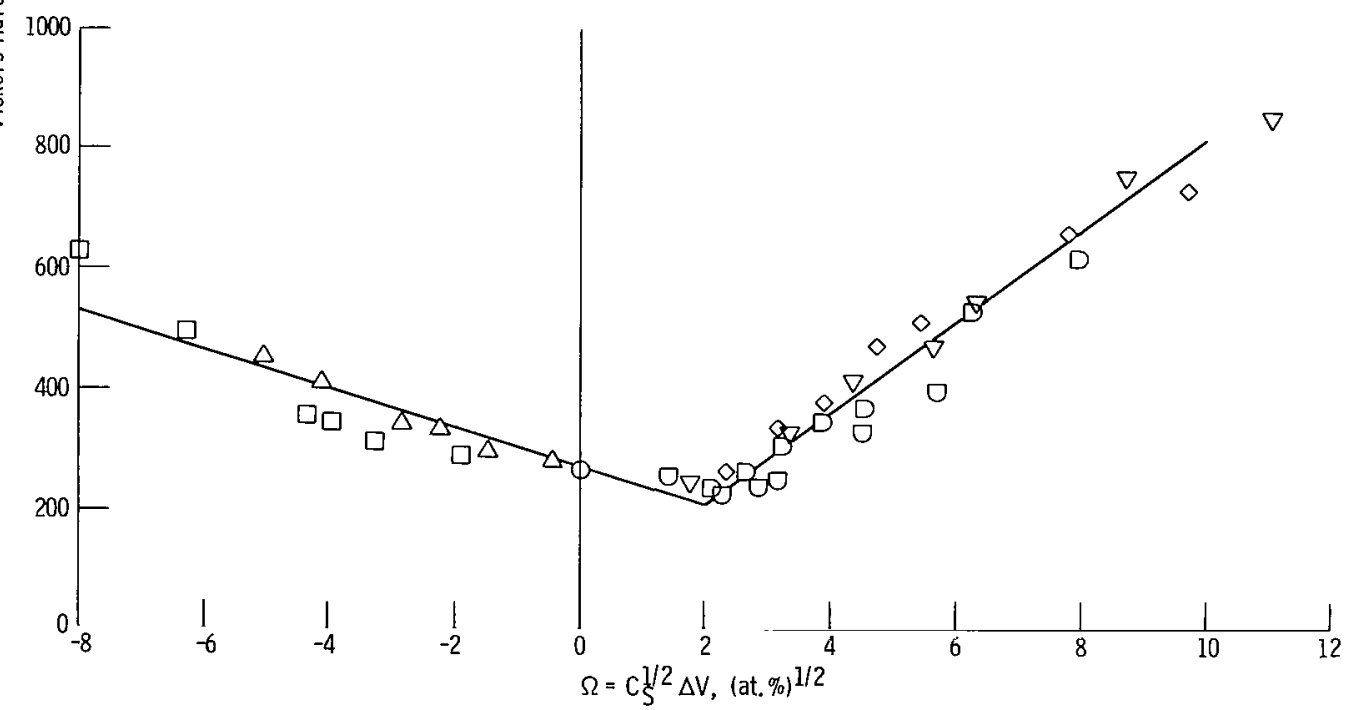

(b) $188 \mathrm{~K}$.

Figure 11. - Effect of square root of solute content and difference in electron concentration on hardness of binary Mo alloys. 


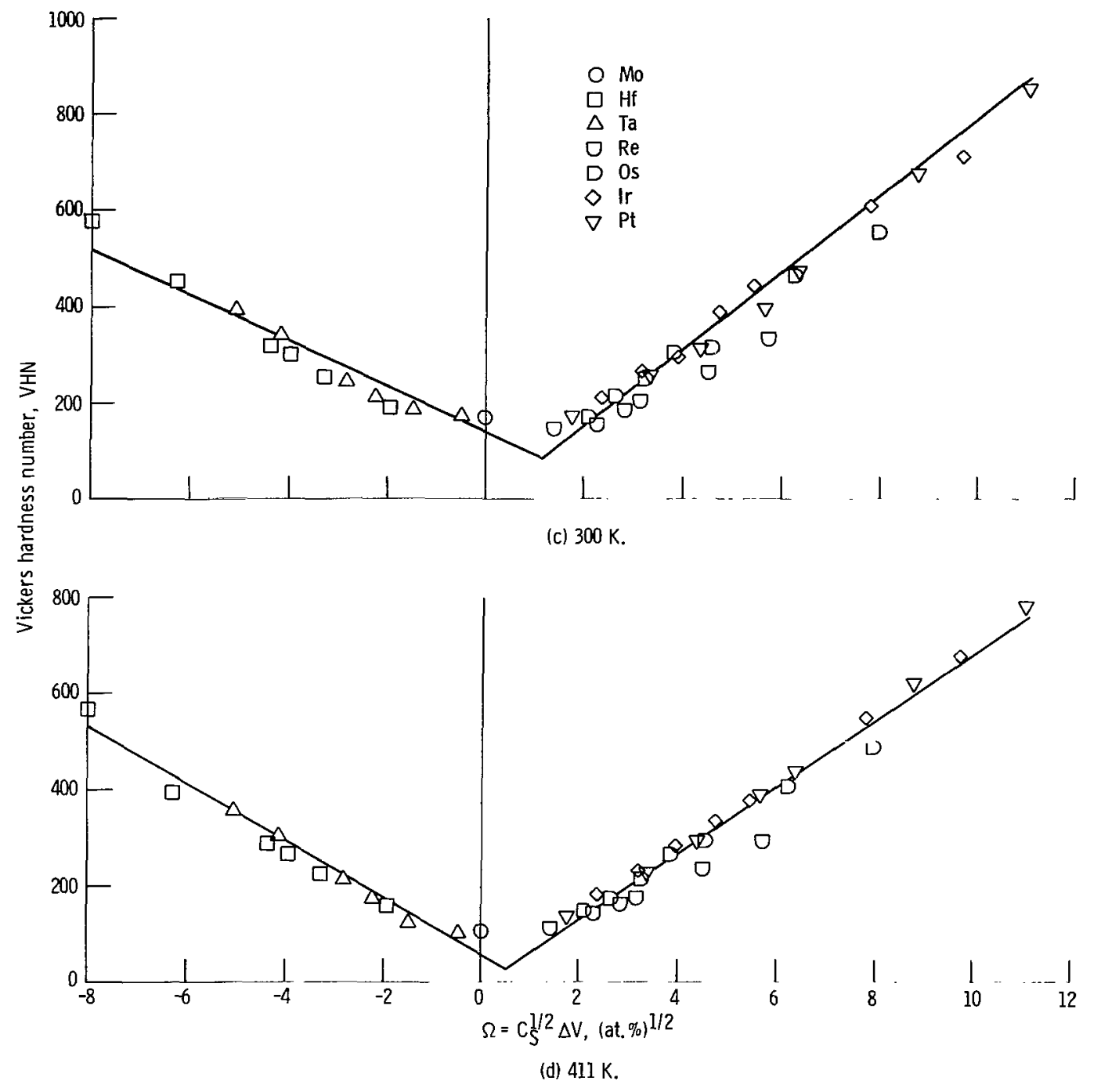

Figure 11. - Concluded.

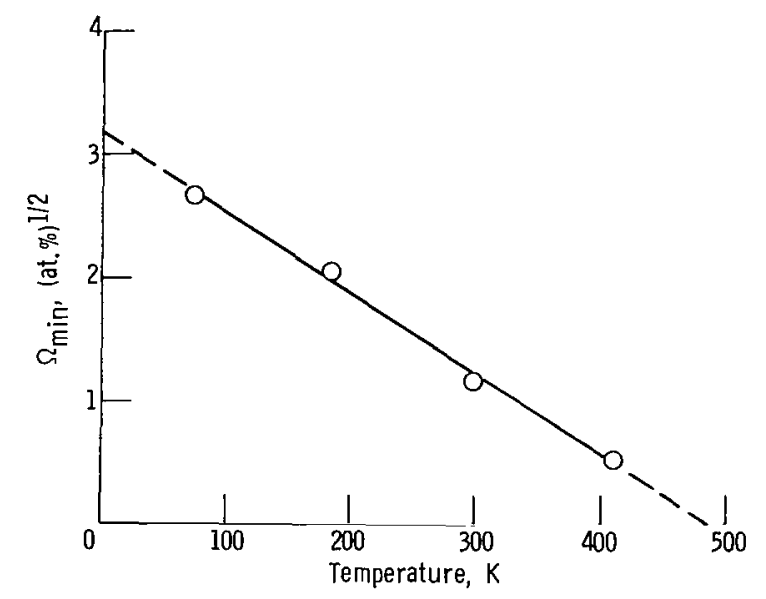

Figure 12. - Temperature dependency of $\Omega_{\min }$. 


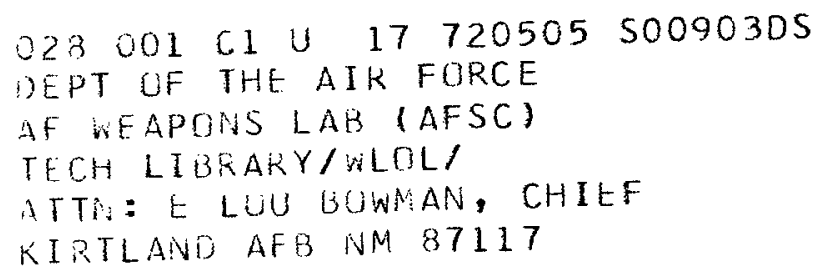

"The aeronautical and space activities of the United States sball be conducted so as to contribute ... to the expansion of buman knowledge of phenomena in the atmosphere and space. The Administration shall provide for the widest practicable and appropriate dissemination of information concerning its activities and the results thereof."

- National Aeronautics and Space ACt of 1958

\section{NASA SCIENTIFIC AND TECHNICAL PUBLICATIONS}

TECHNICAL REPORTS: Scientific and technical information considered important, complete, and a lasting contribution to existing knowledge.

TECHNICAL NOTES: Information less broad in scope but nevertheless of importance as a contribution to existing knowledge.

\section{TECHNICAL MEMORANDUMS:}

Information receiving limited distribution because of preliminary data, security classification, or other reasons.

CONTRACTOR REPORTS: Scientific and technical information generated under a NASA contract or grant and considered an important contribution to existing knowledge.
TECHNICAL TRANSLATIONS: Information published in a foreign language considered to merit NASA distribution in English.

SPECIAL PUBLICATIONS: Information derived from or of value to NASA activities. Publications include conference proceedings, monographs, data compilations, handbooks, sourcebooks, and special bibliographies.

\section{TECHNOLOGY UTILIZATION} PUBLICATIONS: Information on technology used by NASA that may be of particular interest in commercial and other non-aerospace applications. Publications include Tech Briefs, Technology Utilization Reports and

Pechnology Surveys.

Details on the availability of these publications may be obtained from:

SCIENTIFIC AND TECHNICAL INFORMATION OFFICE

NATIONAL AERONAUTICS AND SPACE ADMINISTRATION Washington, D.C. 20546 